\title{
Reciprocal control of obesity and anxiety-depressive disorder via a GABA and serotonin neural circuit
}

\author{
Guobin Xia ${ }^{1}$ Yong Han ${ }^{1} \cdot$ Fantao Meng ${ }^{1} \cdot$ Yanlin He $\mathbb{B}^{1,7} \cdot$ Dollada Srisai $^{2} \cdot$ Monica Farias $^{1} \cdot$ Minghao Dang $^{3} \cdot$ \\ Richard D. Palmiter ${ }^{4,5} \cdot$ Yong Xu $\mathbb{C}^{1,6} \cdot \mathrm{Qi}$ Wu $\mathbb{D}^{1}$
}

Received: 12 August 2020 / Revised: 22 January 2021 / Accepted: 12 February 2021 / Published online: 26 March 2021

(c) The Author(s) 2021. This article is published with open access

\begin{abstract}
The high comorbidity between obesity and mental disorders, such as depression and anxiety, often exacerbates metabolic and neurological symptoms significantly. However, neural mechanisms that underlie reciprocal control of feeding and mental states are largely elusive. Here we report that melanocortin 4 receptor (MC4R) neurons located in the dorsal bed nucleus of the stria terminus (dBNST) engage in the regulation of mentally associated weight gain by receiving GABAergic projections from hypothalamic AgRP neurons onto $\alpha 5$-containing $\mathrm{GABA}_{\mathrm{A}}$ receptors and serotonergic afferents onto $5-\mathrm{HT}_{3}$ receptors. Chronic treatment with a high-fat diet (HFD) significantly blunts the hyperexcitability of AgRP neurons in response to not only hunger but also anxiety and depression-like stimuli. Such HFD-mediated desensitization reduces GABAergic outputs from AgRP neurons to downstream $\mathrm{MC} \mathrm{R}^{\mathrm{dBNST}}$ neurons, resulting in severe mental dysregulation. Genetic enhancement of the $\mathrm{GABA}_{\mathrm{A}} \mathrm{R}-\alpha 5$ or suppression of the $5-\mathrm{HT}_{3} \mathrm{R}$ within the $\mathrm{MC}_{4} \mathrm{R}^{\mathrm{dBNST}}$ neurons not only abolishes HFD-induced anxiety and depression but also robustly reduces body weight by suppression of food intake. To gain further translational insights, we revealed that combined treatment of zonisamide (enhancing the $\mathrm{GABA}_{\mathrm{A}} \mathrm{R}-\alpha 5$ signaling) and granisetron (a selective 5- $\mathrm{HT}_{3} \mathrm{R}$ antagonist) alleviates mental dysfunction and yields a robust reversal of diet-induced obesity by reducing total calorie intake and altering food preference towards a healthy low-fat diet. Our results unveil a neural mechanism for reciprocal control of appetite and mental states, which culminates in a novel zonisamide-granisetron cocktail therapy for potential tackling the psychosis-obesity comorbidity.
\end{abstract}

\section{Introduction}

Obesity is a growing epidemic and is emerging as one of the leading health concerns over the recent two decades, with

These authors contributed equally: Guobin Xia, Yong Han

Supplementary information The online version contains supplementary material available at https://doi.org/10.1038/s41380021-01053-w.

Qi Wu

qiw@bcm.edu

1 USDA/ARS Children's Nutrition Research Center, Department of Pediatrics, Baylor College of Medicine, Houston, TX, USA

2 Department of Molecular Physiology \& Biophysics, Vanderbilt University School of Medicine, Nashville, TN, USA

3 Department of Genomic Medicine, University of Texas MD Anderson Cancer Center, Houston, TX, USA an estimate of nearly 1 in 2 adults in the USA to be developing obesity by 2030 [1-3]. Meanwhile, mental deficiency is among the most common behavioral traits in obese patients and genetic animal models predisposed to obesity [2, 4]. It has been reported that $43 \%$ of adults with depression are obese, and that adults who suffered from mental illnesses are more likely to be obese than those who are mentally healthy [4]. Although peripheral inflammation, hormonal dysregulation, and genetic deficiency is proposed to play a role in the comorbidity of obesity and mental

4 Departments of Biochemistry and Genome Sciences, University of Washington, Seattle, WA, USA

5 Howard Hughes Medical Institute, University of Washington, Seattle, WA, USA

6 Department of Molecular and Cellular Biology, Baylor College of Medicine, Houston, TX, USA

7 Present address: Pennington Biomedical Research Center, Brain Glycemic and Metabolism Control Department, Louisiana State University, Baton Rouge, LA, USA 
disorders, the neural circuit mechanism and associated key neurotransmitter pathways are poorly understood [5-9].

AgRP neurons in the hypothalamus play a fundamental role in the control of appetite and body weight by sending broad projections to intra-and extra-hypothalamic targets including the paraventricular hypothalamic nucleus (PVH), lateral hypothalamic area $(\mathrm{LH})$, paraventricular thalamic nucleus (PVT), and parabrachial nucleus (PBN) [10-19]. Meanwhile, emerging evidence shows that AgRP neurons engage in the control of diverse physiological processes including circadian rhythm, fertility, and pain sensation [20-22]. It is noteworthy that AgRP neurons modulate stereotypic responses during abnormal nutrient states $[13,23]$. AgRP neurons also contribute to fasting-induced anxiolytic effects [24]. Together, these recent studies support a notion that a unique AgRP neural circuit may integrate peripheral hormonal signals with a category of metabolism-sensitive mental functions.

It has been established that GABA co-released from AgRP neurons promotes feeding and weight gain by the integration of various nutritional, hormonal, and neuronal signals $[25,26]$. A class of benzodiazepine agonists, which acts through a specific binding site on $\mathrm{GABA}_{\mathrm{A}}$ receptors, induces hyperphagia by enhancing food and taste palatability in every mammalian species studied [27]. Acute ablation of AgRP neurons or genetic inactivation of GABA signaling of young adult mice resulted in severe loss of body weight and abnormal glucose metabolism [28-30]. Pharmacological manipulation of AgRP postsynaptic targets within the $\mathrm{PBN}$ with a $\mathrm{GABA}_{\mathrm{A}}$ receptor partial agonist, bretazenil, prevented starvation due to AgRP-neuron ablation, indicating that $\mathrm{GABA}_{\mathrm{A}} \mathrm{R}$ signaling is vital for regulation of AgRP neurons [17].

The bed nucleus of the stria terminalis (BNST) acts as a hub for emotional and psychological regulation by making broad, hierarchical, connections with numerous brain regions [31]. The literature suggests that various subpopulations of intermingled neurons in the BNST are implicated to regulate neuroendocrine and behavioral processes through distinct $\mathrm{GABA}_{\mathrm{A}}$ and 5-HTR family receptors [31-35]. For example, genetic disruption of $\mathrm{GABA}_{\mathrm{A}}-\alpha 1$ signaling within the BNST corticotropinreleasing factor $\mathrm{CRF}$ )-expressing neurons increased anxiety-like behavior, coincident with an increase in plasma corticosterone concentration [36]. Treatment of $\mathrm{GABA}_{\mathrm{A}}$ receptor agonist, muscimol or antagonist, picrotoxin within the BNST alleviates or enhances anxiety and depression responses, respectively [33]. Further, picrotoxin can block inhibitory postsynaptic currents of a subgroup of BNST PKC- $\delta$ neurons that inhibit feeding [37]. It is reported that multiple 5-HT receptor subtype mRNAs were expressed in BNST with correlation to mental states [38-40]. Although peripheral 5- $\mathrm{HT}_{3} \mathrm{R}$ signaling is reported to mediate obesity in mice [41-43], the central serotoninergic signaling pathways that engage comorbidity of obesity and emotional deficiency are largely unknown.

In this report, we found that the dorsal BNST (dBNST) plays a pivotal role in a reciprocal control of obesity and mood disorder comorbidity. GABAergic projections from AgRP neurons to the melanocortin 4 receptor (MC4R) neurons located in the dBNST modulates high-fat diet (HFD)induced anxiety and depression-like responses. Genetic enhancement of the $\mathrm{GABA}_{\mathrm{A}} \mathrm{R}-\alpha 5$ signaling or suppression of the $5-\mathrm{HT}_{3} \mathrm{R}$ signaling in the dBNST MC4R neurons not only abolishes mental dysfunction, but also robustly reduces food intake and body weight. More surprisingly, we demonstrate that a cocktail of zonisamide and granisetron by targeting $\mathrm{GABA}_{\mathrm{A}} \mathrm{R}-\alpha 5$ and $5-\mathrm{HT}_{3} \mathrm{R}$ pathways, respectively, restores mental normality and promotes weight loss via altering food preference towards a healthy low-fat diet.

\section{Results}

\section{HFD-induced anxiety and depression correlates with the desensitization of AgRP neurons}

Numerous studies showed that diet-induced obesity is associated with anxiety/depression-like responses [6, 8, 44]. To examine the comorbidity of obesity and associated behavioral phenotypes in an animal model, 8-12-week-old male and female wild-type (WT) mice were fed with a $40 \%$ HFD or standard low-fat diet (LFD) for 6 weeks. At the end of the 6-week treatment, mice fed with HDF exhibited a small but significant increase in body weight in comparison to LFD-fed group (extended data Fig. 1a, b). To assess the anxiety and depression responses, we employed several behavioral assays, including the open-field test (OFT), elevated-plus-maze test (EPM), tail-suspension test (TST), forced-swim test (FST), and marble-burying test (MBT) in the daytime [45-47]. Echoing recent findings that HFD leads to rhythmic changes in locomotor activity during the nighttime but not daytime [21, 48], our behavioral assays performed in daytime were observed with no significant difference in total locomotion between LFD and HFD groups (extended data Fig. 1c-f). However, HFD-fed mice spent significantly less time in the center zone in the OFT compared to the LFD group (Fig. 1a-c). In addition, chronic HFD treatment induced a significant decrease in both duration and entries of open arm in the EPM test (Fig. 1d-f). Moreover, HFD-fed mice showed profound depression-like responses in the FST, TST, and MBT (extended data Fig. 1g-i). All of these results suggested that anxiety/depression-like responses developed along with chronic HFD treatment $[6,8,44]$. 

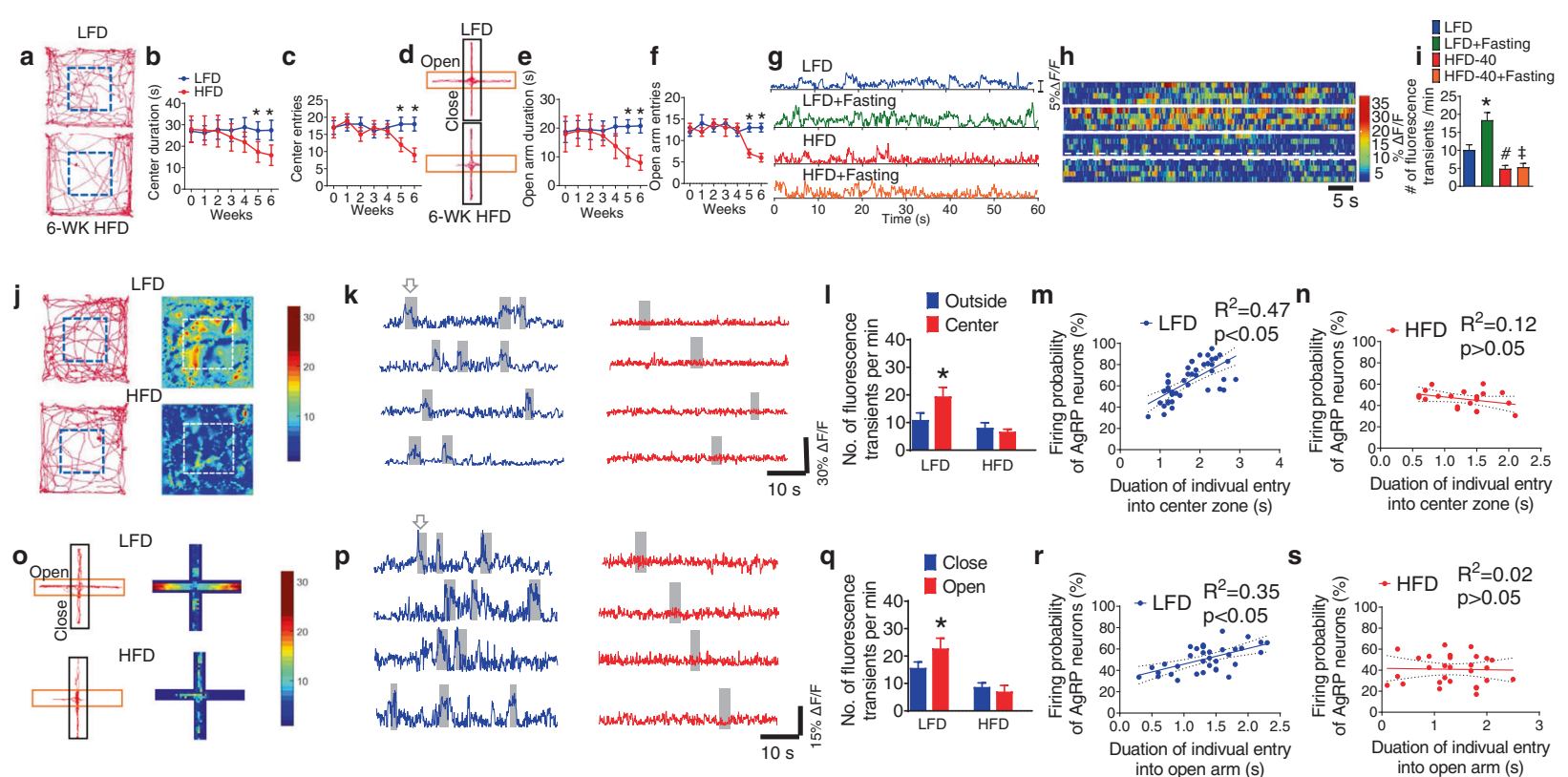

Fig. 1 HFD-induced anxiety and depression correlate with the desensitization of AgRP neurons. a Representative activity tracers in OFT by WT mice fed with chow and 6 week of HFD. b Time spent in the center zone of the open field. $\mathbf{c}$ Entries of entering the center zone of the open field by mice fed with chow and HFD for 6 week. d Representative activity tracers in EPM in WT mice fed with chow and 6 week of and HFD. e Time spent in the open arm. $\mathbf{f}$ Entries of mice entered the open arm. Error bars represent mean \pm SEM. $n=9-12$ per group; ${ }^{*} p<0.05$, LFD vs HFD at week 5 and 6 , two-way ANOVA and followed by Bonferroni comparisons test. $\mathbf{g}$ Representative in vivo fluorescence traces of AgRP neurons in $A g r p{ }^{C r e}$ mice with injection of $A A V 9-F L E X-G C a M P 6 f$ into the ARC after chronic treatment of HFD or low-fat diet (LFD) under fed ad-lib or fasted condition. $\mathbf{h}$ Heat map of color-coded changes of fluorescence intensity in mice as described in (g). $\mathbf{i}$ The numbers of fluorescence transients detected in AgRP neurons in mice as described in (g). Error bars represent mean \pm SEM. $n=10$ per group; $* p<0.05$, LFD vs LFD + Fasting; ${ }^{\#} p<0.05$, LFD vs HFD; ${ }^{\ddagger} p>0.05$, HFD vs HFD + Fasting; one-way ANOVA and followed by Tukey comparisons test. $\mathbf{j}$ Representative physical activity tracers (left) and heating maps of real-time AgRP neuronal activities (right) in OFT test in Agrp $^{\text {Cre }}$ mice injected with AAV9-FLEX-GCaMP6f into the ARC

We utilized fiber photometry in vivo to assess whether chronic treatment of HFD plays a role in AgRP neuronal activity under various metabolic conditions (extended data Fig. 1j-1). In LFD-treated mice, overnight fasting caused hyperexcitability of AgRP neurons which was indicated by virally transduced calcium sensors (Fig. 1g-i) [49-51]. On the other hand, chronic exposure to HFD for 5 weeks not only reduced the basal activity of AgRP neurons but also abolished the fasting-induced hyperexcitability of AgRP neurons (Fig. 1g-i), indicating that HFD treatment desensitizes AgRP neurons in response to hunger signals. We further examined the activity level of AgRP neurons in the context of real-time physical locations during the OFT and EPM assays after chronic treatment of HFD [51]. Control animals when located in the center zone of OFT (denote in followed with a chronic treatment of HFD or LFD under well-fed condition. Gray bars denote when the mice were within the center zone. k Representative in vivo fluorescence traces of AgRP neurons during OFT behavior test. I The number of fluorescence transients detected in AgRP neurons. m Correlation between the probability of AgRP neurons firing and the duration of the LFD-treated mice in the center zone of OFT. $\mathbf{n}$ Correlation between the probability of AgRP neurons firing and the duration of HFD-treated mice in the center zone of OFT. o Representative activity tracers (left) and heating maps (right) in EPM test in Agrp $^{C r e}$ mice injected with AAV9-FLEX-GCaMP6f into the ARC followed with a chronic treatment of HFD or control low-fat diet (LFD) under well-fed and fasting condition. Gray bars denote when the mice were in the open arm. p Examples of in vivo fluorescence changes of AgRP neurons during EPM behavior test. q The number of fluorescence transients detected in AgRP neurons. $\mathbf{r}$ Correlation between the probability of AgRP neurons firing and the duration of the LFD fed mice in the open arm of EPM. s Correlation between the probability of AgRP neurons firing and the duration of HFD-fed mice in the open arm of EPM. Error bars represent mean \pm SEM. $n=10$ per group; $* p<0.05$, one-way ANOVA and followed by Tukey comparisons test.

the gray boxes) exhibited hyperactivity of AgRP neurons (Fig. 1j-1). In contrast, HFD-treated mice had reduced AgRP hyperexcitability, correlating with the reduced duration and entries in the center (Fig. 1j-1). Statistical analyses suggested that the probability of AgRP neuronal hyperexcitability in LFD-treated mice is highly correlated with the duration of individual entry into the center zone, whereas such correlation is drastically diminished in HFDtreated mice (Fig. 1m, n). Similar to OFT results, the control mice in EPM showed significantly enhanced AgRP hyperactivity when entering the open arm (denote in the gray boxes) (Fig. 1o-q). We found a positive correlation between the duration of individual entry into the open arm and the hyperactivity of AgRP neurons (Fig. 1r). In contrast, chronic HFD significantly blunted AgRP hyperactivity and 


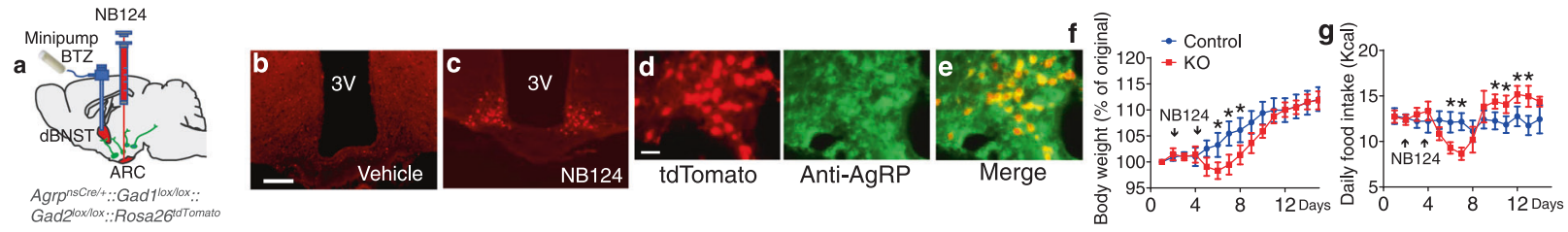

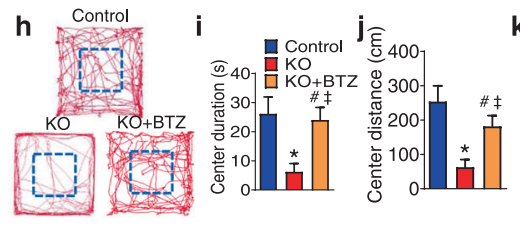
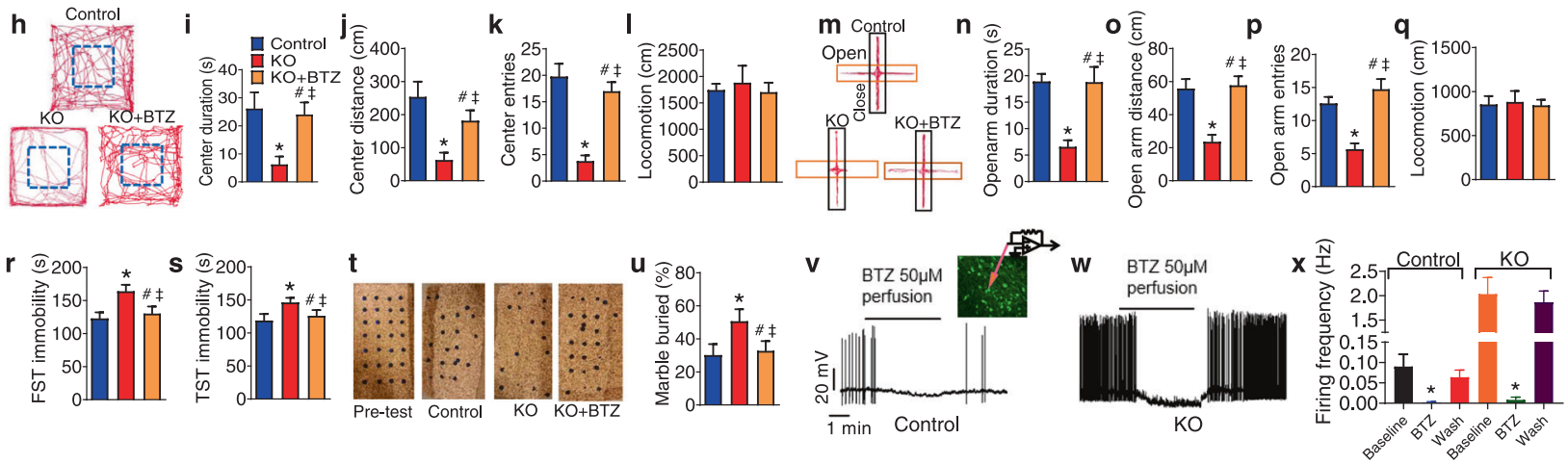

Fig. 2 GABAergic AgRP neurons modulate anxiety and depression by projection to the dBNST. a Schematic image showing abrupt inactivation of GABAergic efferent of AgRP neurons followed by facilitating GABA signaling within the dBNST. b, c Expression of tdTomato (red) in $\operatorname{Agrp}^{n s C r e l+}: \because G a d 1^{\text {lox } / l o x}:: G a d 2^{\text {lox } / l o x}: \because$ Ai14 mice with vehicle (b, control mice) and NB124 (c, KO mice) injection into the third ventricle. Scale bars in (b) for (b, c), $300 \mu \mathrm{m}$. d, e Co-localization of tdTomato and anti-AgRP in ARC after treating $\operatorname{Agrp}^{n s C r e /+} .:$ Gad1 $1^{l o x / l o x}:: G a d 2^{l o x / l o x}: \because$ Ai14 mice with NB124. Scale bar in (d) for (d, e), $100 \mu \mathrm{m}$. f, g Body weight (f), and daily food intake (g) by the control and $\mathrm{KO}$ mice. $\mathbf{h}$ Representative activity tracers in OFT by mice as described in (b) and (c) with a chronic infusion of either vehicle or BTZ $(1 \mathrm{mg} / \mathrm{ml})$ into the dBNST. l-o Time spent in the center zone (l), distance traveled in the center zone $(\mathbf{m})$, the entries into the center zone $(\mathbf{n})$, and total distance traveled in OFT (o). p Representative activity tracers in EPM by mice as described in (h). q-t Time spent in the open arm $(\mathbf{q})$, distance traveled in the open arm $(\mathbf{r})$, the entries into the open

disrupted its correlation with the time of each appearance in the open arms (Fig. 1s). Collectively, our results suggest that the anxiety-depressive responses are mediated by HFDinduced desensitization of AgRP neurons.

\section{GABAergic AgRP neurons modulate anxiety and depression by projection to the dBNST}

To identify the role of AgRP neurons and key neurotransmitter signaling molecules that contribute to mental functions, we take advantage of a newly established inducible genetic method to abruptly inactivate GABA biosynthesis in AgRP neurons [29]. Immunohistochemistry and $\mathrm{qPCR}$ results showed that central administration of NB124, a nonsense-codon suppressor, into the third ventricle of $\operatorname{Agrp}^{n s C r e}:: G a d 1^{l o x / l o x}:: G a d 2^{l o x} / / o x:: A i 14$ mice $\left(\mathrm{AgRP} \mathrm{GABA}^{\mathrm{GO}}\right.$ mice) resulted in expression of full-length, functional, Cre recombinase thereby effectively inactivating GABAergic signaling in AgRP neurons 4 days after drug treatment (Fig. 2a-e and extended data Fig. 2a) [29]. In line arm (s), and total distance traveled in OFT (t). $\mathbf{u}, \mathbf{v}$ Immobility time in FST (u) and TST (v) by mice as described in (h). w Representative images of the MBT by mice as described in (h). $\mathbf{x}$ Percentage of the number of buried marbles in the MBT. Error bars represent mean \pm SEM. $n=7-14 ; * p<0.05$, Control vs KO; one-way ANOVA and followed by Tukey comparisons test. h Firing activity of zsGreenlabeled dBNST neurons before and after treatment with BTZ $(50 \mu \mathrm{M})$ in $\mathrm{Agrp}{ }^{\mathrm{Cr} /+} .: \mathrm{Ai} 14$ mice with an injection of $A A V-D I O-W G A-z s G r e e n$ into the ARC. i Firing activity of zsGreen-labeled dBNST neurons before and after treatment with BTZ $(50 \mu \mathrm{M})$ in Agrp $^{\text {nsCre/ }}::$ Gadl ${ }^{\text {lox }}$ ${ }^{l o x}:: G a d 2^{l o x} / l o x:: A i 14$ mice with an injection of NB124 and $A A V-D I O$ WGA:ZsGreen into the ARC. j Firing frequency of the ZsGreenlabeled dBNST neurons described in $(\mathbf{H}$ and $\mathbf{I})$. Error bars represent mean \pm SEM. $n=11-20$ per group; ${ }^{*} p<0.05$, Baseline vs BTZ in control mice; and $* p<0.05$, Baseline vs BTZ in KO mice; one-way ANOVA and followed by Tukey comparisons test.

with our previous findings, $\mathrm{AgRP}^{\mathrm{GABA}-\mathrm{KO}}$ mice showed a transient but significant reduction of feeding and body weight after acute deletion of GABA signaling from AgRP neurons (Fig. 2f, g). Further, AgRP ${ }^{\mathrm{GABA}-\mathrm{KO}}$ mice exhibited a significantly enhanced anxiety-like responses in both the OFT and EPM assays (Fig. 2h-q). Moreover, AgRP GABA-KO mice showed profound depression-like responses in the FST, TST, and MBT assays (Fig. 2r-u). To test whether loss of GABAergic inputs to the dBNST contributes to the anxiety-depressive phenotypes, BTZ was infused into the dBNST of AgRP ${ }^{\mathrm{GABA}-\mathrm{KO}}$ mice for 14 days. Importantly, these mental deficits were almost completely prevented by the chronic infusion of BTZ into the dBNST (Fig. 2h-u and extended data Fig. 3a-k). Results from the HPLC-MS assay indicated that the concentration of BTZ at nearby locations including the vBNST, LSv, IPACM, and CSF from the LV was significantly lower than that within the targeted dBNST (extended data Fig. 4a, b). To better understand the connectivity of AgRP neurons and dBNST, injection of ZsGreen-tagged wheat germ agglutinin (WGA), a Cre- 


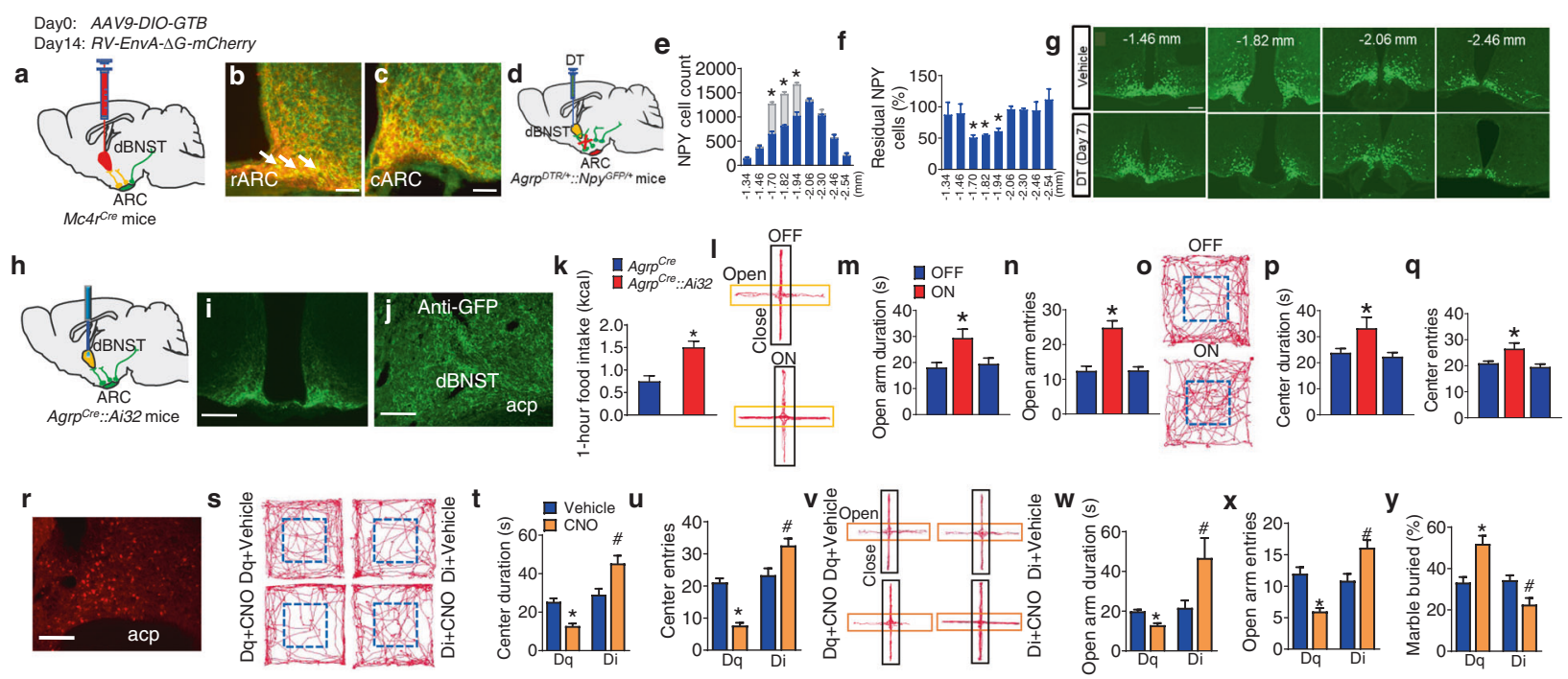

Fig. 3 The $\mathrm{ARC}^{\mathrm{AgRP}}$-dBNST ${ }^{\mathrm{MC} 4 \mathrm{R}}$ circuit mediates metabolismassociated anxiety and depression and feeding of HFD. a Schematic image of retrograde labeling of $\mathrm{AgRP}^{\mathrm{ARC} \rightarrow \mathrm{dBNST}}$ neurons by injecting $A A V 9-D I O-G T B$ and $R V$-EnvA- $\Delta G$ - $m$ Cherry viruses into the dBNST of $M c 4 r^{C r e}$ mice. b, c Overlay of rabies-mCherry and anti-AgRP within the rostral (b) and caudal (c) ARC in mice as described in (a). Scale bar in (b), $50 \mu \mathrm{m}$; scale bar in (c), $50 \mu \mathrm{m}$. d Diagram showing ablation of the BNST-projecting AgRP neurons via bilateral injection of DT or vehicle into the dBNST of $N_{p y}{ }^{G F P /+}:: A g r p^{D T R /+}$ mice. e, $\mathbf{f}$ Number (e) and ratio (f) of NPY neurons in mice as described in (e). $\mathbf{g}$ Representative images showing AgRP neurons (green) in mice as described in (e). Data represent the mean $\pm \mathrm{SEM}, n=6-8$ per group; $*_{p}<0.05$; one-way ANOVA and followed by Tukey post hoc test. $\mathbf{h}$ Photostimulation of AgRP axonal terminals within the dBNST of
Agrp $^{\text {Cre }}::$ Ai32 mice. i, j Immunostaining of anti-GFP (green) within the ARC (i) and dBNST (J) of $\operatorname{Agrp}^{\mathrm{Cre}}::$ Ai32 mice. Scale bar in (i), $400 \mu \mathrm{m}$; scale bar in $(\mathbf{j}), 150 \mu \mathrm{m}$. k 1-h food intake of Agrp $^{\text {Cre }}::$ Ai32 mice upon photostimulation in the dBNST for $10 \mathrm{~min}$ at $20 \mathrm{~Hz}$. $\mathbf{l}-\mathbf{q}$ EPT (1-n) and OFT (o-q) test of $\operatorname{Agrp}^{\mathrm{Cre}}:$ :Ai32 mice upon photostimulation in the dBNST. Error bars represent mean \pm SEM. $n=7$ per group; $* p<0.05$; two-way ANOVA and followed by Bonferroni comparisons test. $\mathbf{r}$ Viral transduction pattern of $M c 4 r^{C r e}$ mice with an injection of AAV9-FLEX-hM3Dq-mCherry into the dBNST. Scale bar in $(\mathbf{r}), 150 \mu \mathrm{m}$. s-y EPM $(\mathbf{s}-\mathbf{u})$, OFT $(\mathbf{v}-\mathbf{x})$, and MBT $(\mathbf{y})$ by the mice as described in (r) upon CNO treatment. Error bars represent mean \pm SEM. $n=8-10$ per group; $* p<0.05$; two-way ANOVA and followed by Bonferroni comparisons test.

expression of GFP-TVA-B19-glycoprotein in MC4R ${ }^{\mathrm{dBNST}}$ neurons (Fig. 3a), followed by injections of EnvA-G-deleted Rabies-mCherry into the dBNST. Application of this retrograding strategy, we observed that neurons within the ARC that project to the MC4 $\mathrm{R}^{\mathrm{dBNST}}$ neurons comprised of a cohort of AgRP neurons (overlay as yellow) and other neuronal populations (as mCherry) that likely include a subset of POMC neurons (Fig. 3b, c and extended data Fig. 6a-c). The mapping results revealed that dBNSTprojecting AgRP neurons were predominantly situated in the rostral ARC (Fig. 3b, c). We performed another profiling experiment by selective ablation of NPY/AgRP neurons that project to the dBNST in $A_{g r p}{ }^{D T R}:: N p y^{G F P}$ mice with DT administration into the dBNST (Fig. 3d and extended data Fig. 8). Consistent with the retrograde tracing study, a significant loss of GFP-labeled NPY neurons was observed in the rostral ARC (Fig. 3e-g). Together, these results indicate that AgRP neurons located in the rostral ARC send long-range projections to $\mathrm{MC} \mathrm{R}^{\mathrm{dBNST}}$ neurons. While the $\mathrm{CRF}^{\mathrm{dBNST}}$ neurons are involved in the regulation of anxious behaviors [34, 38], histological results indicated that MC4 $\mathrm{R}^{\mathrm{dBNST}}$ neurons are a neuronal population distinct from the $\mathrm{CRF}^{\mathrm{dBNST}}$ neurons (extended data Fig. 6d-i). Further,
To further establish the connectivity between AgRP neurons and the dBNST, we performed a Cre-dependent, rabies-based, retrograde mapping of the AgRP $\rightarrow$ dBNST neural circuit [53]. AAV9-DIO-GTB virus was injected into the dBNST of $M c 4 r^{C r e}$ mice to allow specific 


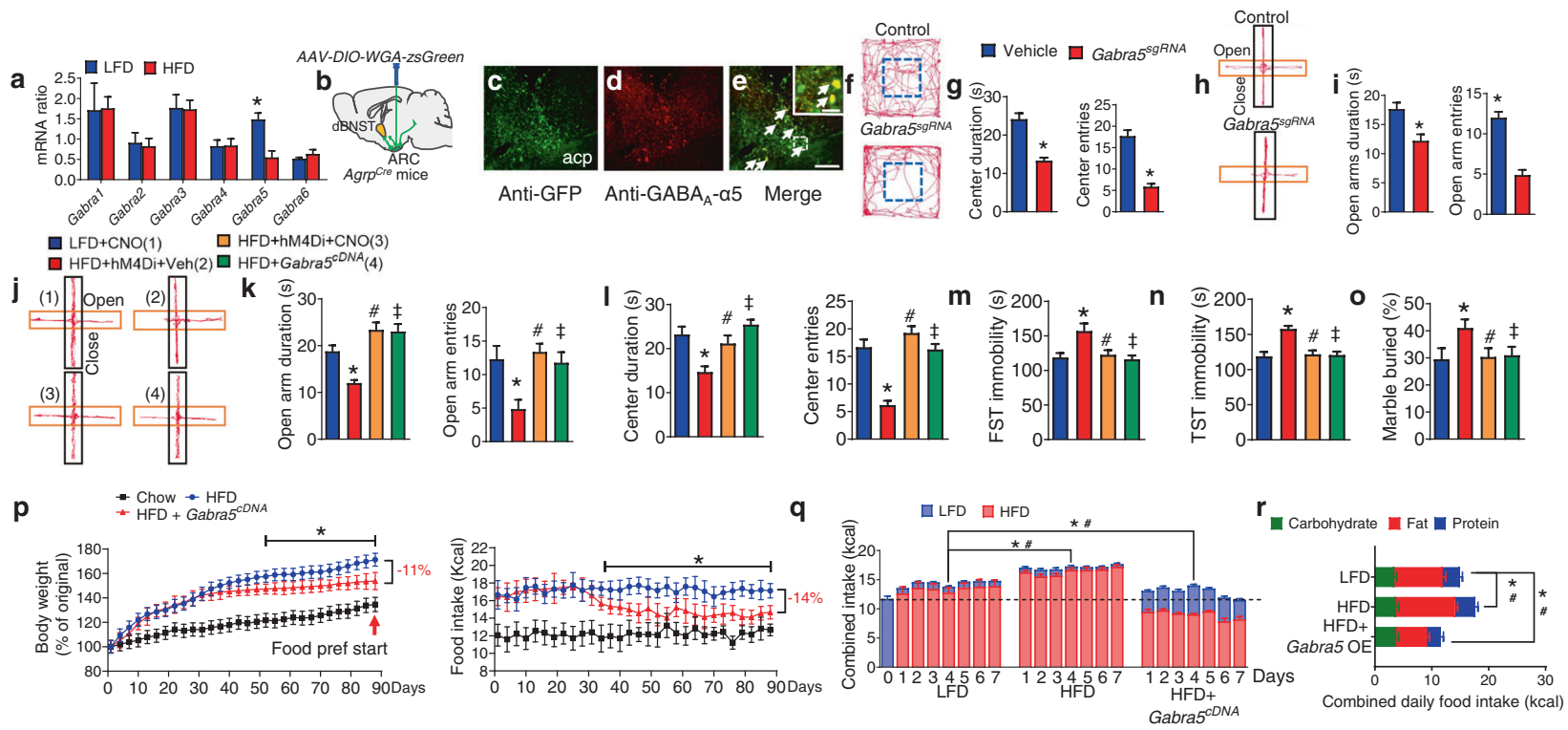

Fig. $4 \mathrm{GABA}_{\mathrm{A}}-\alpha 5$ within the $\mathrm{MC}^{-} \mathrm{R}^{\mathrm{dBNST}}$ neurons mediates HFDinduced mental dysfunction and obesity. a Expression level of major $\mathrm{GABA}_{\mathrm{A}} \mathrm{R}-\alpha 5$ subunits within the dBNST of WT mice treated with LFD or HFD Error bars represent mean \pm SEM. $n=9$ per group; ${ }^{*} p<$ 0.05; two-way ANOVA and followed by Bonferroni comparisons test. b Diagram showing the trans-synaptic tracing by injection of $A A V 9$ FLEX-WGA-ZsGreen into the ARC of Agrp ${ }^{C r e}$ mice. c-e Colocalization of the dBNST neurons directly innervated by AgRP neurons (c) and $\mathrm{GABA}_{\mathrm{A}} \mathrm{R}-\alpha 5$ (e). Inset in (e) is a magnified view of the boxed area showing colocalized neurons with arrow heads. Scale bar in (e) for $(\mathbf{c}-\mathbf{e}), 150 \mu \mathrm{m}$; scale bar in the inset of $(\mathbf{e}), 30 \mu \mathrm{m}$. f-i OFT (f, g), and EPM test $(\mathbf{h}, \mathbf{i})$ by $M c 4 r^{\text {Cre }}: \because \operatorname{Rosa} 26^{\text {Cas } 9}$ mice with bilateral injection of either vehicle (Vehicle), AAV9-FLEXGabra5 ${ }^{\text {sgRNA }}$-tdTomato (Gabra5 ${ }^{\mathrm{sgRNA}}$ ) into the dBNST. Error bars represent mean \pm SEM. $n=7-10$ per group; $* p<0.05$; one-way ANOVA and followed by Tukey comparisons test. $\mathbf{j}-\mathbf{o}$ EPM (j, k), OFT (l), FST (m), TST (n), and MBT (o) test in CNO or vehicletreated $M c 4 r^{C r e}$ mice with either AAV9-FLEX-hM4Di-mCherry or

no overlapping profile was observed between the MC4R signaling and a group of BNST PKC- $\delta$ neurons recently reported to regulate inflammation-associated modulation of feeding (extended data Fig. 9a-f) [37].

In line with previous circuit mapping and functional studies, we found that photostimulation of channelrhodopsin (ChR2) expressed in AgRP-axonal terminals within the dBNST of $A_{g r p}{ }^{c r e}::$ Ai32 mice promoted acute feeding (Fig. 3h-k) [11, 16, 54]. Moreover, photostimulation of AgRP ${ }^{\text {ARC-dBNST }}$ neurons caused a significant anxiolytic phenotype as revealed by OPT and EPM test (Fig. 31-q and extended data Fig. 6j-m). In addition, chemogenetic stimulation of MC4R ${ }^{\mathrm{dBNST}}$ neurons led to profound anxiety and depression-like phenotypes, while inhibition produced a robust anxiolytic and anti-depressant performance in all the behavioral paradigms. (Fig. 3r-y, extended data Fig. 6n-t, and extended data Fig. 7). These data demonstrate that the $\mathrm{ARC}^{\mathrm{AgRP}}{ }_{-\mathrm{dBNST}}{ }^{\mathrm{MC} 4 \mathrm{R}}$ circuit plays a vital role in appetiteinduced mental dysfunctions and chronic feeding.
AAV9-FLEX-Gabra5 ${ }^{\text {cDNA }}$-tdTomato into the dBNST followed with a chronic treatment of HFD or LFD. Error bars represent mean \pm SEM. $n=8$ per group; ${ }^{*} p<0.05, \mathrm{LFD}+\mathrm{CNO}$ vs HFD $+\mathrm{hM} 4 \mathrm{Di}+\mathrm{Veh} ;{ }^{\#} p$ $>0.05, \mathrm{LFD}+\mathrm{CNO}$ vs $\mathrm{HFD}+\mathrm{hM} 4 \mathrm{Di}+\mathrm{CNO} ;{ }^{\ddagger} p>0.05, \mathrm{LFD}+$ CNO vs HFD + Gabra5 ${ }^{c D N A}$; one-way ANOVA and followed by Tukey comparisons test. p Body weight (left) and daily food intake (right) in LFD or HFD-treated $M c 4 r^{\text {Cre }}$ mice with injection of AAV9FLEX-Gabra $5^{\text {cDNA }}$-tdTomato into the dBNST. Error bars represent mean \pm SEM. $n=9$ per group; $* p<0.05$, HFD vs HFD + Gabra5 ${ }^{\mathrm{sgRNA}}$; two-way ANOVA and followed by Bonferroni comparisons test. $\mathbf{q}$ Combined intake of HFD and LFD in a food preference test in mice as described in (J). Error bars represent mean \pm SEM. $n=9$ per group; $* p<0.05$, LFD vs Gabra $5^{\text {cRNA }}$ and HFD vs Gabra $5^{\text {cRNA }}$ in the intake of LFD; ${ }^{\#} p<0.05$ LFD vs Gabra $5^{\text {cRNA }}$ and HFD vs Gabra $5^{\text {cRNA }}$ in the intake of HFD. Two-way ANOVA and followed by Bonferroni comparisons test. $\mathbf{r}$ Macronutrient composition of daily food intake by the mice as described in (p).

\section{$\mathrm{GABA}_{\mathrm{A}}-\mathrm{a} 5$ within the $M C 4 \mathrm{R}^{\mathrm{dBNST}}$ neurons regulates anxiety-depressive disorders and obesity}

We evaluated the effect of chronic HFD on $\mathrm{GABA}_{\mathrm{A}} \mathrm{R} \alpha$ subunits profiles by qPCR, which revealed that Gabra5 mRNA (encoding $\mathrm{GABA}_{\mathrm{A}} \mathrm{R}-\alpha 5$ subunit) within the $\mathrm{MC} \mathrm{R}^{\mathrm{dBNST}}$ neurons was greatly reduced after $5 \mathrm{wk}$ of HFD (Fig. 4a). We also found that $\mathrm{GABA}_{\mathrm{A}} \mathrm{R}-\alpha 5$ is expressed in post-synaptic neurons within the dBNST that were labeled with trans-synaptic WGA:ZsGreen tracer virally transduced by AgRP neurons (Fig. 4b-e). CRISPR/Cas9-mediated genetic deletion of $\mathrm{GABA}_{\mathrm{A}} \mathrm{R}-\alpha 5$ signaling within the

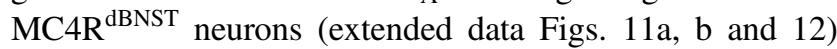
promoted anxiety and depression phenotypes (Fig. $4 \mathrm{f}-\mathrm{i}$ and extended data Fig. 10a-g). Conversely, either chemogenetic suppression of MC4R $\mathrm{R}^{\mathrm{dBNST}}$ neurons or overexpression of $\mathrm{GABA}_{\mathrm{A}} \mathrm{R}-\alpha 5$ within $\mathrm{MC} 4 \mathrm{R}^{\mathrm{dBNST}}$ neurons protected against HFD-mediated anxiety and depression without side effects on locomotion (Fig. 4j-o and extended data Fig. 10h-n). 


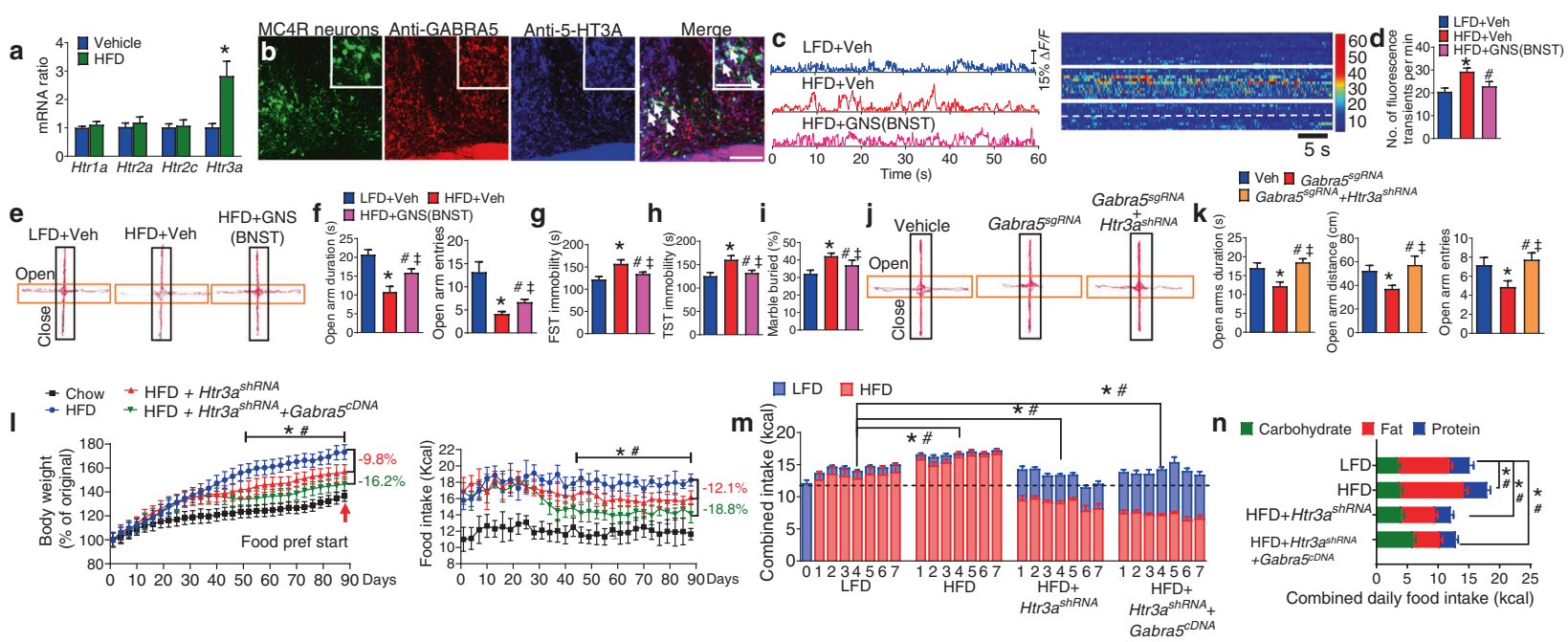

Fig. 5 Synergistic effect of the $5-H_{T} R$ and $G A B A_{A} R-\alpha 5$ signaling within the MC4 ${ }^{\mathrm{dBNST}}$ neurons on HFD-induced mental deficiency and obesity. a Expression level of Htrla-3a and Htr2c in the dBNST of WT mice treated with LFD or HFD. B Co-localization of MC4R neurons with both $\mathrm{GABA}_{\mathrm{A}} \mathrm{R}-\alpha 5$ and $5-\mathrm{HT}_{3} \mathrm{~A}$ signaling within the dBNST. Inset in (b) is a magnified view showing colocalized neurons with arrow heads. Scale bar in (b), $150 \mu \mathrm{m}$. scale bar in inset of (b), 50 $\mu \mathrm{m}$. Error bars represent mean \pm SEM. $n=9$ per group; $* p<0.05$; two-way ANOVA and followed by Bonferroni comparisons test. c Examples of in vivo fluorescence traces in GNS or vehicle-treated $M c 4 r^{C r e}$ mice with AAV9-FLEX-GCaMP6f into the dBNST followed with a chronic treatment of HFD or LFD (left). Right, Heat map of color-coded changes of fluorescence intensity in the mice as described in (C). d The number of fluorescence transients detected in MC4R ${ }^{\mathrm{dBNST}}$ neurons. Error bars represent mean \pm SEM. $n=10$ per group; $* p<0.05$, LFD + Veh vs HFD + Veh; ${ }^{*} p<0.05$, HFD + Veh vs HFD + GNS; one-way ANOVA and followed by Tukey comparisons test. e-i The EPM (e, f), FST (g), TST (h), and MBT (i) test by the mice as described in (c). Error bars represent mean \pm SEM. $n=7-9$ per group; $* p<0.05$, LFD + Vehicle vs HFD + Vehicle; ${ }^{*} p<0.05$, HFD + Vehicle vs HFD + GNS; ${ }^{\ddagger} p>0.05$, LFD + Vehicle vs HFD + GNS. one-way ANOVA and followed by Tukey comparisons test. $\mathbf{j}, \mathbf{k}$

Together, these findings suggest that GABAergic signaling onto $\mathrm{MC}_{4} \mathrm{R}^{\mathrm{dBNST}}$ neurons regulates $\mathrm{HFD}$-induced anxiety and depression by a mechanism involving $\mathrm{GABA}_{\mathrm{A}} \mathrm{R}-\alpha 5$ subunits.

To study the contribution of $\mathrm{GABA}_{\mathrm{A}} \mathrm{R}-\alpha 5$ to the control of food intake and body weight, mice with overexpression of $\mathrm{GABA}_{\mathrm{A}} \mathrm{R}-\alpha 5$ within the $\mathrm{MC} 4 \mathrm{R}^{\mathrm{dBNST}}$ neurons were exposed to ad libitum HFD for 3 months. Strikingly, we found that mice with gain-of-function manipulation of $\mathrm{GABA}_{\mathrm{A}} \mathrm{R}-\alpha 5$ within the $\mathrm{MC} 4 \mathrm{R}^{\mathrm{dBNST}}$ neurons exhibited a late onset, but potent, attenuation of food intake and reduction of body weight (Fig. 4p). Furthermore, results from food-preference assays performed during days 86-92 demonstrated a switch of food choice from the HFD towards an LFD (Fig. 4q-r), illustrating that manipulation of the $\mathrm{GABA}_{\mathrm{A}} \mathrm{R}-\alpha 5$ signaling within the MC4R ${ }^{\mathrm{dBNST}}$ neurons has therapeutic potential.
OFT test by $M c 4 r^{\text {Cre }}: \because \operatorname{Rosa} 26^{\text {Cas } 9}$ mice with a bilateral injection of either vehicle (Vehicle), AAV9- FLEX-Gabra5 ${ }^{\text {sgRNA }}$-tdTomato (Gab$\mathrm{ra}^{\mathrm{sgRNA}}$ ), or AAV9-FLEX-Gabra5 ${ }^{\text {sgRNA }}$-tdTomato and AAV9-FLEX$H \operatorname{tr} 3 a^{\text {shRNA }}-E Y F P\left(\mathrm{Gabra}^{\mathrm{sgRNA}}+\mathrm{Htr} 3 \mathrm{a}^{\text {shRNA }}\right)$ into the dBNST. Error bars represent mean \pm SEM. $n=6-8$ per group; $* p<0.05$, Vehicle vs Gabra5 $5^{\text {sRNA }} ;{ }^{\#} p<0.05$, Gabra $5^{\text {sgRNA }}$ vs Gabra $5^{\text {sgRNA }}+$ Htr $3 a^{\text {shRNA }}{ }^{\ddagger} p$ $>0.05$, Vehicle vs Gabra5 $5^{\mathrm{sRNA}}+\mathrm{Htr} 3 \mathrm{a}^{\text {shRNA }}$; one-way ANOVA and followed by Tukey comparisons test. L Body weight (left) and daily food intake (right) in LFD or HFD-treated $M c 4 r^{C r e}:: R o s a 26^{\text {Cas9 }}$ mice with injection of AAV9-FLEX-Htr3a $a^{\text {shRNA }}$ EYFP or combined AAV9FLEX-Gabra5 $5^{\text {sgRNA }}$-tdTomato and AAV9-FLEX-Htr $3 a^{\text {shRNA }}$-EYFP $\left(\mathrm{Gabra}^{\text {sgRNA }}+\mathrm{Htr} 3 \mathrm{a}^{\text {shRNA }}\right)$ into the dBNST. Error bars represent mean \pm SEM. $n=9$ per group; $* x<0.05$, HFD vs HFD $+\mathrm{Htr} 3 \mathrm{a}^{\text {shRNA }}$; two-way ANOVA and followed by Bonferroni comparisons test. $\mathbf{m}$ Combined intake of HFD and LFD in a food preference test following the assay in the mice described in (I). Error bars represent mean \pm SEM. $n=9$ per group; ${ }^{*} p<0.05$, LFD vs Htr $3 \mathrm{a}^{\text {shRNA }}$ and HFD vs $\mathrm{Htr} 3 \mathrm{a}^{\text {shRNA }}$ in the intake of LFD; ${ }^{\#} p<0.05$ LFD vs Htr $3 \mathrm{a}^{\text {shRNA }}$ and HFD vs Htr3a ${ }^{\text {shRNA }}$ in the intake of HFD. Two-way ANOVA and followed by Bonferroni comparisons test. n Macronutrient composition of daily food intake by the mice described in (I).

\section{The $5-\mathrm{HT}_{3} \mathrm{R}$ and $\mathrm{GABA}_{\mathrm{A}} \mathrm{R}-\mathrm{a} 5$ pathways elicit synergistic effects on anxiety-depressive behavior and obesity}

We also examined the HFD-mediated expression profile of 5 -HT receptor subtypes within the $\mathrm{MC} 4 \mathrm{R}^{\mathrm{dBNST}}$ neurons and found that $\mathrm{Htr} 3 \mathrm{a}$ (encoding the $5-\mathrm{HT}_{3} \mathrm{R}$ subunit A) showed the most robust elevation upon long-term treatment of HFD (Fig. 5a). Our immunostaining results indicated that both $\mathrm{GABA}_{\mathrm{A}} \mathrm{R}-\alpha 5$ and $5-\mathrm{HT}_{3} \mathrm{R}$ receptors were co-localized within $\mathrm{MC}_{4} \mathrm{R}^{\mathrm{dBNST}}$ neurons (Fig. 5b). In contrast, MC4R ${ }^{\mathrm{dBNST}}$ neurons did not co-express 5-HT1A (extended data Fig. 13a-f). The in vivo fiber photometry results revealed that $M C 4 R^{\mathrm{dBNST}}$ neurons are hyperexcitable after chronic treatment with the HFD, an effect that was blocked by treatment of granisetron (GNS), a selective $5-\mathrm{HT}_{3} \mathrm{R}$ antagonist (Fig. 5c, d). Infusion of GNS into the dBNST 
effectively rescued HFD-induced anxiety and depression (Fig. 5e-i and extended data Fig. 13g-k).

We further examined the functional relevancy of $\mathrm{GABA}_{\mathrm{A}} \mathrm{R}-\alpha 5$ and $5-\mathrm{HT}_{3} \mathrm{R}$ in the regulation of mental states and body weight using combined CRISPR/Cas and RNAi techniques. AAV9-FLEX-Gabra5 ${ }^{s g R N A}$-tdTomato injected into the dBNST of $M c 4 r^{\text {Cre }}::$ Rosa26 ${ }^{\text {Cas } 9-E G F P}$ mice (extended data Fig. 14a-b) led to elevated anxiety and depression, which was fully prevented by additional injection of AAV9FLEX-Htr $3 a^{\text {shRNA }}$-EYFP into the dBNST (extended data Fig. 131-o). However, neither of these manipulations altered basal locomotion (extended data Fig. 13s, t). To assess whether the manipulation of $H t r 3 a$ within $\mathrm{MC}^{\mathrm{d}} \mathrm{R}^{\mathrm{dBNST}}$ neurons contributes to the regulation of HFD-induced anxiety-depressive behavior and body weight, mice deficient in Htr3a within MC4R ${ }^{\mathrm{dBNST}}$ neurons were subjected to chronic exposure to ad lib HFD for 3 months. We found that loss of $5-\mathrm{HT}_{3} \mathrm{R}$ from $\mathrm{MC}_{4} \mathrm{R}^{\mathrm{dBNST}}$ neurons fully rescued anxiety and depression after 35 days of viral treatment (Fig. 5j, k and extended data Fig. 13p-w). More strikingly, these mice exhibited a late onset, but potent, attenuation of food intake and reduction of body weight after treatment of HFD (Fig. 51). Furthermore, results from food-preference assays demonstrated a switch of food choice from HFD towards an LFD (Fig. 5m, n). Together, these results indicate that genetic suppression of 5- $\mathrm{HT}_{3} \mathrm{R}$ or enhancement of $\mathrm{GABA}_{\mathrm{A}} \mathrm{R}-\alpha 5$ within $\mathrm{MC} 4 \mathrm{R}^{\mathrm{dBNST}}$ neurons is sufficient to revert mental dysfunction which in turn normalizes food consumption and body weight.

\section{A combo pharmacotherapy alleviates HFD-induced anxiety/depression and reverses obesity}

Evidence suggests that zonisamide (ZNS), an anticonvulsant medication, suppresses food intake and renders moderate weight loss in various preclinical and clinical trials [55-59]. However, the mechanisms underlying appetite regulation are unknown at both cellular and circuitry level. Here we found that ZNS, when infused into the dBNST, potently suppressed HFD-induced hyperexcitability of MC4R ${ }^{\mathrm{dBNST}}$ neurons (Fig. $6 \mathrm{a}-\mathrm{c}$ ). In addition, there was a significant decrease in daily food intake of ZNStreated mice after chronic HFD feeding (Fig. 6d). Behavioral tests revealed that intra-dBNST treatment with ZNS completely rescued HFD-induced anxiety and depression without affecting locomotion (Fig. 6e, f and extended data Fig. 15a-h). To determine how ZNS acts within the dBNST neural circuit, we examine the neuronal activity of MC4R ${ }^{\mathrm{dBNST}}$ neurons upon CRISPR/Cas9-mediated deletion of the $\mathrm{GABA}_{A} \mathrm{R}-\alpha 5$ signaling. The fiber photometry results showed that intra-dBNST infusion of ZNS significantly reduced the activity of MC4 $\mathrm{R}^{\mathrm{dBNST}}$ neurons, whereas ZNSmediated suppressive effect was nullified by removal of
$\mathrm{GABA}_{\mathrm{A}} \mathrm{R}-\alpha 5$ from these neurons (Fig. $6 \mathrm{~g}-\mathrm{j}$ ). Furthermore, the behavioral results indicated that ZNS-mediated anxiolytic and anti-depression effects were abolished after deletion of Gabra5 from MC4R ${ }^{\mathrm{dBNST}}$ neurons (Fig. 6k, 1 and extended data Fig. 15i-s). These data suggest that ZNS mediates anxiety and depression responses by acting through the $\mathrm{GABA}_{\mathrm{A}} \mathrm{R}-\alpha 5$ signaling in $\mathrm{MC} 4 \mathrm{R}^{\mathrm{dBNST}}$ neurons.

These encouraging results suggested that combined treatment with ZNS and GNS might confer additive effects over the control of HFD consumption and obesity. To test this hypothesis, mice were subjected to chronic exposure to HFD for 3 months with intra-dBNST infusion of combined ZNS and GNS. Behavioral results indicated that both systemic administration or intra-dBNST infusion of combined ZNS and GNS produced profound anxiolytic and antidepression effects (Fig. 6m-r and extended data Fig. 15t-v). Notably, this combo treatment of ZNS and GNS reversed diet-induced obesity by reducing total calorie intake (Fig. 6s-u). Both systemic administration or intra-dBNST infusion of combined ZNS and GNS directed food preference from HFD toward a healthy LFD (Fig. 6v). Furthermore, analysis of macronutrient composition showed that co-administration of ZNS and GNS was associated with a reduction of fat consumption along with a moderate increase of carbohydrate intake, resulting in a much healthier nutrient intake profile (Fig. 6w). Thus, combined administration of ZNS and GNS robustly mitigates HFDinduced anxiety/depression-like behavior and further reverses obesity by rebalancing the composition of macronutrient intake.

\section{Discussion}

Until we have a thorough understanding of the underlying neurobiological mechanisms, effective management of obesity and related emotional comorbidity is a challenging task [60-65]. In the present study, we found that chronic HFD treatment leads to desensitization of AgRP neurons in response to hunger, downregulation of $\mathrm{GABA}_{\mathrm{A}} \mathrm{R}-\alpha 5$ signaling, and upregulation of $5-\mathrm{HT}_{3} \mathrm{R}$ within the post-synaptic MC4 $\mathrm{R}^{\mathrm{dBNST}}$ neurons, rendering abnormal hyperactivity of

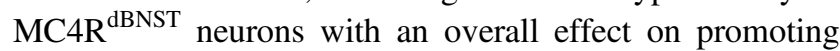
HFD-mediated anxiety and depression (Fig. 6w). Disruption of GABAergic signaling from AgRP neurons led to mental dysfunction, which could be rescued by enhancing $\mathrm{GABA}_{\mathrm{A}} \mathrm{R}$ signaling within downstream dBNST neurons. Furthermore, stimulation of post-synaptic $\mathrm{MC} \mathrm{R}^{\mathrm{dBNST}}$ neurons or genetic inactivation of $\mathrm{GABA}_{\mathrm{A}} \mathrm{R}-\alpha 5$ signaling promoted anxiety and depression-like responses. Conversely, genetic enhancement of $\mathrm{GABA}_{\mathrm{A}} \mathrm{R}-\alpha 5$ or disruption of $5 \mathrm{HT}_{3} \mathrm{R}$ significantly attenuated mental dysfunctions, which in turn contributed to the mitigation of HFD- 

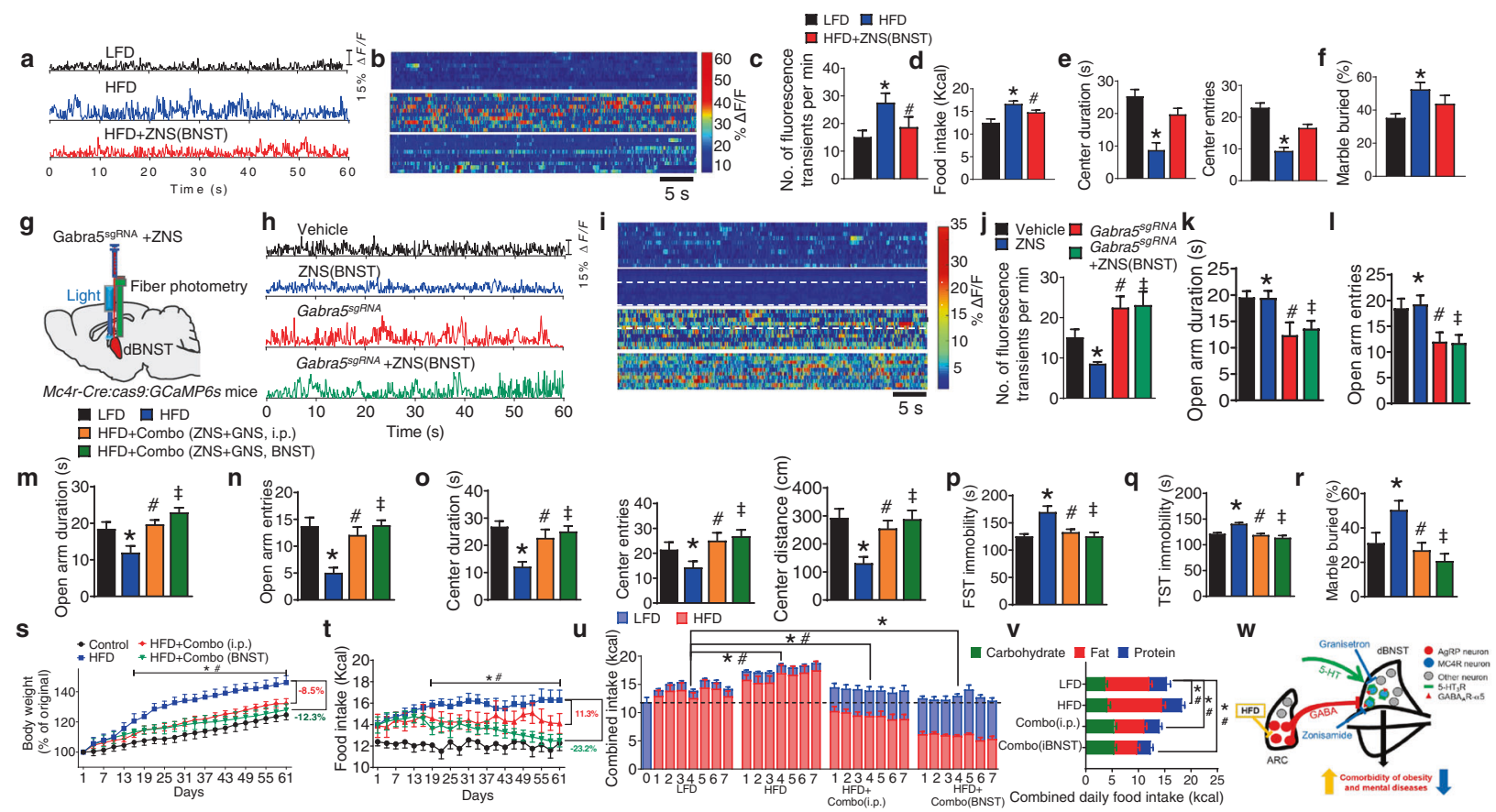

Fig. 6 Combination of zonisamide and granisetron alleviates HFDinduced mental dysfunctions and rescues obesity. a Examples of in vivo fluorescence traces in ad-lib fed $\mathrm{Mcr} 4^{\mathrm{Cre}}$ mice with $A A V 9$ FLEX-GCaMP6f into the dBNST followed with a chronic treatment of LFD or HFD or HFD combined with injection of ZNS into the dBNST. b Heat map of color-coded changes of fluorescence intensity in the mice as described in (a). c The numbers of fluorescence transients detected in MC4R ${ }^{\mathrm{dBNST}}$ neurons of the mice as described in (a). d Daily food intake by WT mice with the chronic treatment of LFD or HFD or HFD combined with injection of ZNS into the dBNST. Error bars represent mean \pm SEM. $n=7-9$ per group; $* p<0.05$, LFD vs HFD; ${ }^{\#} p>0.05$, HFD + ZNS vs LFD. One-way ANOVA and followed by Tukey comparisons test. d, e OFT (d) and MBT (e) assays by the mice as described in (a). f Diagram showing in vivo fiber photometry analysis of $\mathrm{Mc} 4 \mathrm{r}^{\mathrm{dBNST}}$ neurons in response to Gabra5-KO and ZNS. g Examples of in vivo fluorescence traces in ad-lib fed $M c 4 r^{\text {Cre }}:: R o s a 26^{\text {Cas } 9}$ mice with bilateral injection of either vehicle, AAV9-FLEX-Gabra5 $5^{\text {ssRNA }}$-tdTomato (Gabra5 ${ }^{\mathrm{sgRNA}}$ ) into the dBNST, followed by microinjection of vehicle or ZNS into the dBNST. h Heat map of color-coded changes of fluorescence intensity in the mice as described in (g). i The numbers of fluorescence transients detected from the MC4R ${ }^{\mathrm{dBNST}}$ neurons in mice as described in (g). j, k EPM test of the mice described in (g). Error bars represent mean \pm SEM. $n$ $=7-9$ per group; ${ }^{*} p<0.05$, Vehicle vs Gabra5 ${ }^{\mathrm{sgRNA}}$; ${ }^{\#} p<0.05$, Vehicle vs ZNS; ${ }^{\ddagger} p>0.05$, Gabra $5^{\text {sgRNA }}$ vs Gabra5 $5^{\text {sRNA }}+$ ZNS. One-

associated obesity. Furthermore, pharmacological treatment of two clinically approved drugs, ZNS and GNS, acting through $\mathrm{GABA}_{\mathrm{A}} \mathrm{R}-\alpha 5$ and $5 \mathrm{HT}_{3} \mathrm{R}$, respectively, displayed a strong synergistic effect in reversal of HFD-induced mental phenotype and a robust loss of the body weight by switching macronutrient composition to mixture of HFD with a significant amount of healthy LFD.

We demonstrate effective rescuing effects of both anxiety-depressive deficiency and obesity by facilitating $\mathrm{GABA}_{\mathrm{A}} \mathrm{R}$ signaling within the dBNST, genetic suppression way ANOVA and followed by Tukey comparisons test. l-q EPM (l, $\mathbf{m}), \operatorname{OFT}(\mathbf{n}), \operatorname{TST}(\mathbf{o}), \operatorname{FST}(\mathbf{p})$, and MBT (q) assays in WT mice with i. p. or i.c.v injection of both ZNS and GNS into dBNST by chronic HFD feeding. r, s Body weight (r) and food intake (s) in mice with the chronic treatment of LFD or HFD or HFD combined with i.p. injection of ZNS and GNS into the dBNST or HFD combined with microinjection of ZNS and GNS into the dBNST during a 7-week treatment of HFD. Error bars represent mean \pm SEM. $n=7$ per group; ${ }^{*} p<0.05$, HFD vs HFD + ZNS + GNS (i.p.); ${ }^{\#} p<0.05$, HFD vs HFD + ZNS + GNS (BNST); two-way ANOVA and followed by Bonferroni comparisons test. $\mathbf{t}$ Combined intake of LFD and HFD in mice as described in (r) and (s) during the last 7 days of the 7-week treatment of HFD. Error bars represent mean \pm SEM. $n=7$ per group; $* p<0.05$, LFD vs HFD + ZNS + GNS (i.p.), HFD vs HFD + ZNS + GNS (BNST) and $\mathrm{HFD}+\mathrm{ZNS}+\mathrm{GNS}$ (i.p.) vs $\mathrm{HFD}+\mathrm{ZNS}+\mathrm{GNS}$ (BNST) in the intake of LFD; ${ }^{p}$ < $<0.05$, LFD vs HFD + ZNS + GNS (i.p.), HFD vs $\mathrm{HFD}+\mathrm{ZNS}+\mathrm{GNS}$ (BNST) and HFD + ZNS + GNS (i.p.) vs HFD + ZNS + GNS (BNST) in the intake of HFD. Two-way ANOVA and followed by Bonferroni comparisons test. u Macronutrient composition of food intake by the mice as described in (r). v Schematic diagram showing that a cocktail therapy of zonisamide and granisetron by action through the $\mathrm{GABA}_{\mathrm{A}} \mathrm{R}-\alpha 5$ and $5-\mathrm{HT}_{3} \mathrm{R}$ signaling, respectively, within the MC4R $\mathrm{R}^{\mathrm{dBNST}}$ neurons effectively eliminate obesity and mental disorders comorbidity.

of MC4R $\mathrm{R}^{\mathrm{dBNST}}$ neurons, or even a combo pharmacological therapy by administering ZNS and GNS peripherally or directly into the dBNST. The uniqueness of this neural pathway with defined cellular identity and molecular signaling provides mechanistic insights into how the BNST regulates feeding and mental functions $[32,33]$. The profound modulation of $\mathrm{AgRP}^{\mathrm{ARC}} \rightarrow \mathrm{MC} 4 \mathrm{R}^{\mathrm{dBNST}}$ circuit and associated physiological and behavioral outcomes by chronic treatment of HFD. A recent study showed that obesity remodels the activity and transcriptional state of a 
lateral hypothalamic glutamatergic neurons that encode satiety state [66]. Another study indicated that the lateral hypothalamic hypocretin/orexin (Hcrt) neurons were functionally desensitized in obese mice [67]. Take these together, we suggest that HFD-induced obesity was coupled with profound and diversified changes in several neuronal groups. Future efforts of identifying novel circuitry components in the context of the critical $\operatorname{AgRP}^{\mathrm{ARC}} \rightarrow$ MC4 $\mathrm{R}^{\mathrm{BNST}}$ circuit and associated receptor signaling cascades would unveil a more complete neural mechanism for obesity and psychotic comorbidity.

Serotonin system is a major contributor to mood regulation, upon which a wide variety of medications for mental disorders were developed [68]. Recent studies showed that several 5-HT receptor subtypes, including 5$\mathrm{HT}_{1 \mathrm{~A}}, 5-\mathrm{HT}_{2 \mathrm{~A}}, 5-\mathrm{HT}_{2 \mathrm{C}}$, play substantial roles in the mitigation of anxiety and depression [34, 68, 69]. Nevertheless, we found that chronic HFD treatment prompted a robust upregulation of 5- $\mathrm{HT}_{3} \mathrm{R}$ within the BNST MC4R neurons. Treatment of a 5-HT ${ }_{3} \mathrm{R}$ antagonist alleviates HFD-induced anxiety-depressive dysfunction. Furthermore, genetic suppression of $5-\mathrm{HT}_{3} \mathrm{R}$ signaling attenuates both anxiety and depression phenotypes in HFD-fed mice with a subsequent reduction of food intake and weight loss. These results suggest that $5-\mathrm{HT}_{3} \mathrm{R}$ within the $\mathrm{MC} 4 \mathrm{R}^{\mathrm{dBNST}}$ neurons is a unique target for obesity and its mental comorbidity [41].

Our time-course study indicated that prior to development into obesity, animals exposed to chronic HFD treatment display progressive manifestations of anxiety and depression phenotypes (Fig. $1 \mathrm{a}-\mathrm{f}$ and extended data Fig. 1a-i). On the other hand, the rescuing studies showed that both genetic and pharmacological interventions lead to a significant weight loss after HFD feeding. Taken with previously reported clinical studies [4], we suggest a causal relationship between anxiety-depressive responses and obesity. Collectively, targeting $\mathrm{GABA}_{\mathrm{A}} \mathrm{R}-\alpha 5$ and $5 \mathrm{HT}_{3} \mathrm{R}$ within $\mathrm{MC} \mathrm{R}^{\mathrm{dBNST}}$ neurons facilitates the rescue of HFDinduced anxiety and depression disturbance, which in turn lowers body weight by simultaneously reducing the craving of HFD and enhancing feeding of healthy low-fat diets in mice.

Pharmacological studies suggest that central $\mathrm{GABA}_{\mathrm{A}}$ receptor signaling exerts prominent influences on feeding in various brain regions $[17,18,26]$. A class of benzodiazepine agonists, approved for anxiety disorder treatment, which acts through a specific binding site on $\mathrm{GABA}_{\mathrm{A}}$ receptors, induces hyperphagia by enhancing food and taste palatability $[26,70]$. In line with this literature, we found that genetic manipulation of $\mathrm{GABA}_{\mathrm{A}} \mathrm{R}-\alpha 5$ produced profound anti-obesity effects and attenuation in HFD-induced anxiety and depression in mice. It is noteworthy that HFDmediated desensitization of AgRP neurons is coupled with a significant reduction of Gabra5 signaling within the post- synaptic MC4R ${ }^{\mathrm{dBNST}}$ neurons (Fig. 1g-i, and Fig. 4a), demonstrating a functionally hierarchal structure of this neural circuit. Furthermore, we observed an additive antiobesity effect with combined genetic manipulations of 5$\mathrm{HT}_{3} \mathrm{R}$ and $\mathrm{GABA}_{\mathrm{A}} \mathrm{R}-\alpha 5$ within the $\mathrm{dBNST}^{\mathrm{MC} 4 \mathrm{R}}$ neurons, laying a mechanistic foundation for a novel pharmacological intervention by targeting both signaling pathways for obesity and mental comorbidity.

Past clinical trials in an attempt to establish ZNS, a clinically approved anti-convulsant drug, as an anti-obesity medication were largely unsuccessful, largely due to the elusive pharmacological mechanism and marginal effects on weight loss $[55,56,58,59,71]$. We demonstrated here that $\mathrm{ZNS}$ acts through $\mathrm{GABA}_{\mathrm{A}} \mathrm{R}-\alpha 5$ signaling with a robust effect on weight loss and anxiety-depressive recovery. Combined treatment of GNS and ZNS achieved a strong synergistic effect on the reversal of obesity and coinciding mental dysregulation. Our results provide convincing support for the future clinical study by a cocktail therapy with combined treatment of ZNS and GNS, as well as a more comprehensive drug repurposing pipeline for metabopsychiatric diseases [72-74].

\section{Methods}

\section{Animals}

All animal care and experimental procedures were approved by the Institutional Animal Care and Use Committees at Baylor College of Medicine. Mice used for data collection were both males and females, at least eight weeks of age. All animals were kept in temperature- and humiditycontrolled rooms, in a 12/12-h light/dark cycle, with lights on from 7:00 AM-7:00 PM. Food and water were provided ad libitum. A $40 \%$ Kcal fat diet was used (TD.95217, Envigo, Indianapolis, IN) for in vivo fiber photometry and behavioral study. Another $60 \% \mathrm{Kcal}$ fat diet was used (TD.06414, Envigo, Indianapolis, IN) for chronic food intake, body weight, and food preference study.

Genetic Mouse Model. Agrp ${ }^{D T R /+}$ mice [28], Agrp ${ }^{\text {Cre }}$


[29], Npy ${ }^{G F P /+}$ mice [75], Ai14 (or Rosa26 $6^{\text {tdTomato }}$ ) mice [76], Ai32 mice [76], Mc4r ${ }^{\text {Cre }}$ mice [15], and Rosa26 Cas9 mice [77] were produced as described previously. All mice are on a C57B1/6 background with at least eight generations backcrossed.

\section{Brain surgery and viral injections}

Animals were anesthetized by isoflurane and placed on a stereotaxic frame. A 26-gauge stainless steel guide cannula (PlasticsOne, USA) with an infusion dummy cannula was 
placed into the dBNST (coordinates: $+1.0 \mathrm{~mm}, 1.0 \mathrm{~mm}$ lateral from bregma and depth $-4.3 \mathrm{~mm}$ ). To target the ARC the coordinate is: $(-1.7 \mathrm{~mm}, 0.25 \mathrm{~mm} .5 .9 \mathrm{~mm})$. To target the third ventricle the coordinate is: $(-1.7,0.5 .6 \mathrm{~mm})$. The following virus was used in the different experiments: AAV9-FLEX-GCaMP6f, AAV9-DIO-WGA-ZsGreen, AAV9DIO-GTB, EnvA G-deleted RV-mCherry, AAV9-FLEXhM3Dq-mCherry, AAV9-FLEX-hM4Di-mCherry, AAV9Gabra5 ${ }^{\text {sgRNA }}$-tdTomato, AAV9-FLEX-Gabra5 ${ }^{\text {shRNA }}{ }_{\text {-tdTomato, }}$ AAV9-FLEX-Gabra5 ${ }^{\text {cRNA }}$-tdTomato, AAV9-FLEX-Htr $3 a^{\text {shRNA }}$ $E Y F P$, injected bilaterally $(0.3 \mu \mathrm{l}$ per each side) through Hamilton syringe (31 gauge, Model 75 Small RN Syringe) using a pump (UMP3 UltraMicroPump, Sarasota, FL, USA).

\section{Pharmacology}

To disrupt GABAergic inputs from AgRP neurons in adult mice, microinjection of NB124 [29] (two injections of 0.4 $\mathrm{mg} / \mathrm{side}, 2$ days apart; Calbiochem) in 6-week-old Agrp ${ }^{D T R /}$ ${ }_{D T R}$ mice was performed. To chronically infuse bretazenil (BTZ) to the dBNST Alzet micro-osmotic pumps (model 1002, Durect, Cupertino, CA, USA) loaded with $100 \mu \mathrm{l}$ of BTZ (3 mg/ml in saline plus 10\% DMSO; Sigma-Aldrich, St Louis, MO, USA) were implanted subcutaneously on the back of anesthetized mice at 5-month old. These minipumps dispense $0.25 \mu \mathrm{l} / \mathrm{h}$. Specifically, ad libitum fed mice will be euthanized in the morning ( 9 am) 30 days after NB124 injection to harvest the brain tissue for c-Fos staining. The cannulas (28 gauge, Plastics One) were placed into either the third or fourth ventricles under anesthesia, and the subcutaneous Alzet minipumps were connected to the cannulas by tubing (PE60; Stoelting, Wood Dale, IL, USA) that was threaded under the skin to help prevent the mice from dislodging it. To chemogenetic activation or inactivation neurons the mice will be administrated with CNO by bilateral microinjection $(0.4 \mathrm{ng} /$ side $)$ or i.p. injection $(1 \mathrm{mg} / \mathrm{kg})$. To study the effect of $5-\mathrm{HT}$ receptors on anxiety and depression the 5-HT receptors antagonist GNS (0.1 ug/side, Sigma-Aldrich) were i.c.v. administrated.

\section{Food intake and body weight}

Mice were individually housed and allowed to acclimate for $7 \mathrm{~d}$ before experiments were initiated. Consumption of diet pellets and body weight were measured on a daily basis throughout the experimental period.

\section{Open-field test}

To assess locomotor activity and anxiety levels, animals were gently removed from the home cage and placed singly into an open-field arena (Plexiglas cage, $50 \mathrm{~L} \times 50 \mathrm{~W} \times 40 \mathrm{H} \mathrm{cm}$ ).
An automated video-tracking system (Ethovision by Noldus) was used to track multi subjects simultaneously. After the experiment gently returns each mouse to the respective home cage. To avoid olfactory cues the arena (usually $50 \% \mathrm{EtOH}$ ) was carefully wiped after every running. The central area delineated virtually with Ethovision software, is taken as an imaginary inner square $(30 \times 30 \mathrm{~cm})$ of the open filed. The amount of time spent and distance traveled in the center of the chamber compared to the edges, as well as the frequency into center zone and total distance traveled across a session of 5 min were calculated.

\section{Elevated plus maze test}

To assess anxiety levels, animals were removed from their home cages and placed individually into an elevated plus maze. The plus maze consisted of four elevated arms $(30 \mathrm{~L} \times 5 \mathrm{~W} \mathrm{~cm})$ intersected at right angles. Two opposite arms were enclosed by $15-\mathrm{cm}$ high walls, and the other two were open (no walls). The structure was elevated $60 \mathrm{~cm}$ above the floor and mice were placed on the $5 \times 5 \mathrm{~cm}$ intersection of the maze facing into an arm with walls to start a trial. The Ethovision system was used to track multi subjects simultaneously. After the experiment gently returns each mouse to the respective home cage. To avoid olfactory cues the arena (usually 50\% EtOH) was carefully wiped after every running. The amount of time the mice spent and distance traveled in the open arms of the maze, as well as the frequency into open arms and total distance traveled throughout a 5-min session were calculated.

\section{Tail suspension test}

To assess depressive-like behaviors, mice were done with a tail suspension test. Once each piece of tape was attached to a mouse tail stick the middle portion of the tape to the horizontal bar. Once all tape is applied, start the recording and identify the session before the mice are suspended. The whole suspension lasted $6 \mathrm{~min}$. At the end of the session the animals were returned to their home cage and carefully remove the tape from each tail by gently pulling it off. The immobility time was assessed using the Ethovision tracking system.

\section{Forced-swim test}

To assess depressive-like behaviors, mice were performed a forced-swim test. The cylindrical tanks $(40 \mathrm{H} \times 20 \mathrm{D} \mathrm{cm})$ were used in the mouse forced-swim test which are constructed of transparent Plexiglas. A water-resistant infrared thermometer was used to monitor the water temperature. Bring the animals into the testing room for $30 \mathrm{~min}$ rest. Then mice were held by the tail and gently placed in the 
container with $\sim 40 \mathrm{~cm}$ of water $\left(23-25^{\circ} \mathrm{C}\right)$ for $6 \mathrm{~min}$. After the experiment removes the animals from the water by their tails and dry them with drying paper and place back into their home cage. The immobility time was assessed using the Ethovision tracking system.

\section{Marble burying test}

To assess depressive-like behaviors, mice were performed a MBT. A rat cage was filled to $5 \mathrm{~cm}$ of corn-based animal bedding. Twenty-eight black, glass marbles were evenly spaced within the box, and mice were placed in the center with test sessions of $30 \mathrm{~min}$. At the end of the sessions, the numbers of buried marbles (at least to $2 / 3$ depth) were counted for statistical analysis.

\section{Optogenetics}

For in vivo optogenetic stimulation the optic fiber was assembled as described following the protocol [78]. The mice were unilaterally implanted optic fiber in the dBNST. The $1.25 \mathrm{~mm}$ ceramic ferrule with $200 \mu \mathrm{m}$ fiber compatible with $1.25 \mathrm{~mm}$ optogenetics patch cables connected to spectralynx (Neuralynx, Inc, USA) was inserted into the cannula with its projection $0.5 \mathrm{~mm}$ below the guide cannula. Blue light was shined into the dBNST at $20 \mathrm{~Hz}$ frequencies during the behavioral tests.

\section{In Vivo fiber photometry}

For in vivo fiber photometry, $\mathrm{Agrp}{ }^{\mathrm{Cre}}$ or $\mathrm{Mc} 4 r^{\mathrm{Cre}}$ mice were injected AAV9-FLEX-GCAMP6f into the ARC or dBNST. Animals were allowed to recover for at least 2 weeks before experiments proceeded. Optic probes were assembled and implanted following the previous protocol. The $488 \mathrm{~nm}$ laser was used to excite GCaMP6 through the multi-mode fiber patch cord and the QE Pro detector (Ocean optics) was used to collect the photons emitted from the tissue through the multi-mode detection fiber patch cord. The OceanView software (Ocean optics) was used to acquire the data. Spectral channel $(500-543 \mathrm{~nm})$ was selected for GCaMP6. The integrated photon count was used as a measure of intensity. The spectrum data were recorded continuously at $10 \mathrm{~Hz}$ sampling frequency. The percentage $\Delta F / F$ was calculated by $100 \times(F-F$ mean $) / F$ mean, where $F$ mean was the mean fluorescence intensity throughout the entire acquisition fragment. The detection threshold for a fluorescence transient was defined as $\mu+3 \sigma$, where $\mu$ and $\sigma$ were the mean and the standard deviation of the fluorescence baseline period. The fluorescence transients during baseline were randomly sampled (40-45 s). For the heat map the recorded data were saved as ASCII files and opened in MATLAB. And the heat map can be plotted by Matlab.
All Data were analyzed offline using Excel, Matlab, and Prism.

\section{In vitro electrophysiological recordings}

The mice were handled and kept in artificial cerebrospinal fluid (aCSF) as described recently [79]. Animals were subjected to anesthesia, and the handling protocol of the local committee was followed. The slices containing the dBNST in the coronal plane $(250-300 \mu \mathrm{m})$ were prepared. In most case, we have used the same mouse first for the in vivo experiments and immediately after for combined electrophysiology and optogenetics in vitro in order to minimize the number of mice. The whole brain was quickly dissected into ice-cold oxygenated aCSF containing (in $\mathrm{mM}$ ): $130 \mathrm{NaCl}, 5 \mathrm{KCl}, 2.4 \mathrm{CaCl}_{2}, 1.3 \mathrm{MgSO}_{4}, 1.25$ $\mathrm{KH}_{2} \mathrm{PO}_{4}, 10$ glucose, and $20 \mathrm{NaHCO}_{3}, \mathrm{pH} 7.4$ with $\mathrm{NaOH}$, bubbled with a mixture of $95 \% \mathrm{O}_{2}$ and $5 \% \mathrm{CO}_{2}$. Then the brain was cut coronally into $300-\mu \mathrm{m}$ slices on a microtome (VTA-1000S; Leica). Slices containing the aDRN were transferred to an incubation chamber filled with aCSF and incubated for at least $1 \mathrm{~h}$ at room temperature $\left(24-26^{\circ} \mathrm{C}\right)$. At RT, the slices were transferred to a recording chamber on the stage of a fluorescence microscope (BX51WI, Olympus) and maintained immersed and continuously superfused with aCSF at $4-5 \mathrm{ml} / \mathrm{min}$. Patch electrodes were pulled on a micropipette puller (P-97, Sutter Instruments) from borosilicate capillaries (GC150-10, Harvard Apparatus). The pipettes (5-12 $\mathrm{M} \Omega$ ) contained (in $\mathrm{mM}$ ): $97.5 \mathrm{~K}$-gluconate, $32.5 \mathrm{KCl}, 1 \mathrm{MgCl}_{2} \cdot 6 \mathrm{H}_{2} \mathrm{O}, 40$ HEPES, $0.5 \mathrm{Na}-\mathrm{GTP}, 2 \mathrm{Mg}$ ATP, and 0.5 EGTA, pH 7.4. Recordings were made with a MutiClamp 700B amplifier (Molecular Devices). The dBNST neurons were subjected to electrophysiological recordings. The action potentials (APs) were recorded in response to either depolarizing current injection or light expose or DT treatment. Data were acquired and analyzed using Spike2 7.04 software (Cambridge Electronic Design). Patchmaster, Clampfit, Mini Analysis, Origin and Microsoft Excel software were used for data acquisition and subsequent analyses. The current signals were filtered at $1 \mathrm{kHz}$ and the sampling interval was 50-200 $\mu$ s. The number of experiments $(n)$ and means \pm SEM are indicated. Comparisons were assumed significant if $p<0.05$.

\section{FACS}

The tdTomato-positive or EYFP-positive neurons were isolated by a standard flow cytometry method as described [29]. Briefly, brain tissues containing the ARC or the dBNST were collected into $0.5 \mathrm{~mL}$ of ice-cold HBSS buffer, then transferred to $37{ }^{\circ} \mathrm{C}$ warmed dispase buffer (BD Biosciences), and incubated for $15 \mathrm{~min}$. During the incubation period, tissues were gently pipetted up and down 
until completely dissociated. Next, $0.5 \mathrm{~mL}$ ice-cold FACS buffer [10\% (wt/vol) glucose, $0.5 \mathrm{mM}$ EDTA, and $3 \mathrm{mg} / \mathrm{mL}$ BSA] was added to stop the dispase-mediated dissociation process. Cells were pelleted by centrifuging for $2 \mathrm{~min}$ at $3000 \times g$ at $4{ }^{\circ} \mathrm{C}$. The pellets were resuspended in $0.5 \mathrm{~mL}$ of ice-cold FACS buffer and then filtered into polypropylene tubes (Falcon) before the FACS procedure.

\section{Quantitative real-time PCR}

Total RNA was isolated using Trizol reagent (Life technologies) and treated with RQ1 DNase (Promega). First strand cDNA was synthetized by superscript II reverse transcriptase (ThermoFisher Scientific) according to the manufacturer's protocol and quantitative real-time PCR was performed using Taqman Primers. All samples were run in triplicate $25 \mu \mathrm{l}$ reaction $\left(\mathrm{GoTaq}^{\circledR}\right.$ colorless master mix, Promega) using CFX96 q-PCR system (Bio-Rad) and normalized to the GAPDH using the $\Delta \Delta \mathrm{Ct}$ method.

AgRP Neurons Counting. Agrp ${ }^{D T R /+}:: N p y^{G F P /+}$ mice were killed and perfused transcardially with ice-cold PBS buffer ( $\mathrm{pH}$ 7.4) containing 4\% (wt/vol) paraformaldehyde (Alfa Aesar). Brains were collected and postfixed overnight under $4{ }^{\circ} \mathrm{C}$ in a fixation buffer containing $3 \%$ paraformaldehyde. About 90 free-floating sections $(20 \mu \mathrm{m})$ were cut by a microtome (Thermo Fisher) in the arcuate nucleus (ARC) of the hypothalamus and then soaked in ice-cold PBS buffer ( $\mathrm{pH}$ 7.4). After mounting the sections, fluorescent images were captured by a digital camera mounted on a DMI6000B microscope (Leica). The whole ARC was divided into nine segments from anterior to posterior ARC. The neuron numbers of each section were manually counted by using ImageJ plugin Cell Counter (NIH).

\section{Zonisamide (ZNS) treatment}

To demonstrate that ZNS can attenuate the hyperactivity of the dBNST Mc4r neurons, three groups of young male $M c 4 r^{C r e}$ mice were injected with AAV9-FLEX-GCAMP $6 f$ into the dBNST. After recovery, cannula was implanted above the dBNST. The mice were randomly assigned into three groups (LFD, HFD, HFD + ZNS, $n=8$ for each group) and fed with LFD or HFD. For HFD + ZNS group, ZNS ( $5 \mu \mathrm{g} / \mathrm{side} / \mathrm{mouse} /$ day) was i.c.v. injected into the dBNST for 7 days, while the other two groups were injected with the same volume of vehicle. In vivo fiber photometry was conducted at day $0,3,7$.

To test whether modulation of 5-HT signaling in the dBNST can sensitize ZNS's effects on anxiety and depression, four groups of young mice (LFD, HFD, HFD + ZNS, HFD + ZNS + GNS, $n=11$ for each group) were implanted with cannula above the dBNST for drug delivery and fed with LFD or HFD. For HFD + ZNS group, ZNS was i.c.v injected into the dBNST ( $5 \mathrm{ug} / \mathrm{side} / \mathrm{day} /$ mouse), and ZNS ( $5 \mu \mathrm{g} / \mathrm{side} /$ day/mouse) and GNS (0.5 $\mu \mathrm{g} / \mathrm{side} /$ day/mouse) for HFD + ZNS + GNS group, while the LFD and HFD groups were microinjected with the same volume of vehicle.

To elucidate the effect of ZNS is dependent on Gabra5 signaling, young $M c 4 r^{C r e}$ mice were injected with $A A V 9$ FLEX-GCAMP6f and Gabra5 $5^{\text {sgRNA }}$ into the dBNST, fed with HDF, and separately housed. After recovery, cannula was implanted above the dBNST. After 21 days of microinjection of $\mathrm{ZNS}$ at $5 \mu \mathrm{g} / \mathrm{mouse} / \mathrm{day}$, the anxiety and depression behavior paradigm were tested in 10 days. In vivo fiber photometry was conducted at day $0,7,14,21$.

For long-term drug combination study, four groups of young mice were bilaterally implanted with cannula above the dBNST and separately housed. After recovery, mice were fed with control diet $(n=11)$ or HFD $(n=35)$ for 90 days. For HFD + ZNS group $(n=12), 5 \mu \mathrm{g} /$ side/day $/$ mouse were i.c.v. injected into the dBNST, and $5 \mu \mathrm{g} / \mathrm{side} /$ day/mouse $+0.5 \mathrm{ug} /$ side/day/mouse for HFD + ZNS + GNS group $(n=12)$, while the control and HFD groups were microinjected with the same volume of vehicle. Body weight and food intake were measured daily. For food preference study, after the 90-day trial, the mice were presented with both LFD and HFD. The daily food intake of the two diets for each single-caged mouse was recorded.

\section{Immunohistochemistry}

Immunostaining was performed as described with modification [29]. Mice were killed and perfused transcardially with ice-cold PBS buffer (pH 7.4) containing 3\% (wt/vol) paraformaldehyde (Alfa Aesar) and 1\% glutaraldehyde (Sigma). Brains were collected and postfixed overnight under $4{ }^{\circ} \mathrm{C}$ in a fixation buffer containing $3 \%$ paraformaldehyde. Free-floating sections $(20 \mu \mathrm{m})$ were cut by a microtome (Thermo Fisher) and then blocked with 5\% (wt/vol) normal donkey serum in $0.1 \%$ Triton X-100 (TBST buffer, $\mathrm{pH}$ 7.2) for overnight. For each different assay, either rabbit anti-AgRP (1:500 dilution; Phoenix Pharmaceuticals), rabbit anti-Fos (1:1,500 dilution; EMD Millipore), mouse anti-CRF (1:1000 dilution; EMD Millipore), goat anti-5HT3A (1:300 dilution; Abcam), goat anti5HT1A (1:300 dilution; Abcam), rabbit anti-GABAR-A5 (1:400 dilution; Abcam), chicken anti-GFP (1:500 dilution; Life Technologies) was applied to the sections for overnight incubation under $4{ }^{\circ} \mathrm{C}$, followed by $4 \times 15$-min rinses in the TBST buffer. Finally, sections were incubated with Alex Fluor 488-conjugated secondary antibody (1:1000 dilution; Jackson Immunolab) or Alex Fluor cy3-conjugated secondary antibody (1:1000 dilution; Jackson Immunolab) for $2 \mathrm{~h}$ at room temperature, followed by $4 \times 15$-min rinses in TBST buffer. For mounted sections, fluorescent images were captured by a digital camera mounted on a DMI6000B 
microscope (Leica). All images were analyzed by the ImageJ software.

\section{Liquid chromatography with tandem mass spectrometry}

To evaluate the potential diffusion of dBNST-administered BTZ into surrounding brain regions, LC-MS was applied to calculate the BTZ concentrations after injection into the dBNST for $24 \mathrm{~h}$. The LC-MS was performed by the Metabolomics Core at Baylor College of Medicine. Four punches containing the dBNST, vBNST, LSv, and IPACM from fresh brain tissues were collected with a thickness of $1.0 \mathrm{~mm}$ by brain matrix. The wet weights of the brain tissue samples ranged from 8.1 to $15.5 \mathrm{mg}$. For tissue homogenization, the samples were mixed with cold $\left(-20^{\circ} \mathrm{C}\right)$ methanol:water $(1: 1, \mathrm{v} / \mathrm{v})$ containing $60 \mathrm{ppm}$ of the internal standard 4-nitrobenzoic acid in a ratio of $1 \mathrm{mg}$ tissue: $10 \mu \mathrm{L}$ of solvent per mg of tissue [ratio 1:10 (w/v)]. The disruption of the tissue was achieved using a Benchmark Bead Blaster Refrigerated Microtube Homogenizer, 115 V (Benchmark, US) for $2 \mathrm{~min} .100 \mu \mathrm{L}$ of the resulting homogenate was transferred into a $1.5 \mathrm{~mL}$ Eppendorf and mixed with $320 \mu \mathrm{L}$ of cold $\left(-20^{\circ} \mathrm{C}\right)$ methanol. The samples were then vortexmixed for $2 \mathrm{~min}$, followed by air drying. Subsequently, dried samples were reconstituted in $200 \mu \mathrm{L}$ of 50:50 methanol: water $(0.2 \%$ formic acid). After centrifugation at $4000 \times g$ at $20^{\circ} \mathrm{C}$ for $20 \mathrm{~min}, 100 \mu \mathrm{L}$ of the sample was divided into two UHPLC-MS vials with insert $(10 \mu \mathrm{L} / \mathrm{each})$ to inject them directly into the system for LC-MS analyses in positive and negative ionization modes.

BTZ concentrations from the brain tissue samples were acquired using liquid chromatography-mass spectrometry (LC-MS/MS; 6495 QQQ Triple Quadrupole MS, Agilent Technologies). The analysis was carried out on highperformance liquid chromatography (HPLC) system equipped with a quaternary pump, a degasser, an auto sampler, and a column compartment. Mass spectrometric detection was carried out using triple coupled quadrupole equipped with an electron spray ionization (ESI) source. The data acquisition was under the control of Mass Hunter software. The separation of BTZ was achieved using an RRHD SB$\mathrm{CN}$ column $(1.8 \mu \mathrm{m}, 3.0 \times 100 \mathrm{~mm}$, Agilent Technologies $)$. The mobile phase consists of $0.1 \%$ formic acid (A) in water and acetonitrile (B) with gradient elution at a flow rate of $0.3 \mathrm{ml} / \mathrm{min}$. Gradient is spanning $2 \% \mathrm{~B}$ to $98 \% \mathrm{~B}$ over $15 \mathrm{~min}$ followed by $98 \%$ B to $2 \%$ B for $1 \mathrm{~min}$. The typical operating source condition for MS scan in positive ESI mode was optimized $(\mathrm{m} / \mathrm{z}, 417.28$, protonated BTZ).

To evaluate the effects of DT diffusion in the dBNST and surrounding brain regions, the relative score for DT concentration by LC-MS was calculated $24 \mathrm{~h}$ after DT injection into the dBNST. The LC-MS was performed by the Clinical and Translational Proteomics Service Center at the University of Texas Health Science Center. The brain tissues were punched $24 \mathrm{~h}$ after DT ( $0.4 \mathrm{ng}$ ) injection into the dIDRN. Four punches containing the dBNST, vBNST, LSv, and IPACM were collected with a thickness of $1.0 \mathrm{~mm}$ by brain matrix. The brain tissue lysates were subjected to acetone precipitation; proteins were precipitated at $-20{ }^{\circ} \mathrm{C}$ for three hours. After centrifugation $(12,000 \times g \times 5 \mathrm{~min})$, the pellets were resuspended in $10 \mathrm{ml}$ of $150 \mathrm{mM}$ Tris- $\mathrm{HCl}$, $\mathrm{pH} 8.0$, denatured and reduced with $20 \mathrm{ml}$ of $9 \mathrm{M}$ urea, $30 \mathrm{mM}$ DTT in $150 \mathrm{mM}$ Tris $\mathrm{HCl}, \mathrm{pH} 8.0$, at $37^{\circ} \mathrm{C}$ for $40 \mathrm{~min}$, then alkylated with $40 \mathrm{mM}$ iodacetamide in the dark for $30 \mathrm{~min}$. The reaction mixture was diluted 10 -fold using $50 \mathrm{mM}$ Tris- $\mathrm{HCl} \mathrm{pH} 8.0$ prior to overnight digestion at $37^{\circ} \mathrm{C}$ with trypsin (1:20 enzyme to substrate ratio). Digestions were terminated by adding an equal volume of $2 \%$ formic acid, and then desalted using Waters Oasis HLB $1 \mathrm{ml}$ reverse-phase cartridges according to the vendor's procedure. Eluates were dried via vacuum centrifugation.

About 1 microgram of the tryptic digest (in 2\% acetonitrile $/ 0.1 \%$ formic acid in water) was analyzed by LC/ MS/MS on an Orbitrap Fusion Tribrid mass spectrometer (Thermo Scientific) interfaced with a Dionex UltiMate 3000 Binary RSLCnano System. Peptides were separated onto a Acclaim PepMap C18 column $(75 \mathrm{~mm}$ ID $\times 15 \mathrm{~cm}, 2 \mathrm{~mm})$ at a flow rate of $300 \mathrm{nl} / \mathrm{min}$. Gradient conditions were: $3-22 \%$ B for $120 \mathrm{~min}$; $22-35 \%$ B for $10 \mathrm{~min}$; $35-90 \%$ B for $10 \mathrm{~min}$; $90 \% \mathrm{~B}$ held for $10 \mathrm{~min}$,(solvent $\mathrm{A}, 0.1 \%$ formic acid in water; solvent $\mathrm{B}, 0.1 \%$ formic acid in acetonitrile). The peptides were analyzed using data-dependent acquisition method, Orbitrap Fusion was operated with measurement of FTMS1 at resolutions 120,000 FWHM, scan range 350-1500 $\mathrm{m} / \mathrm{z}$, AGC target 2E5, and maximum injection time of $50 \mathrm{~ms}$; During a maximum $3 \mathrm{~s}$ cycle time, the ITMS2 spectra were collected at rapid scan rate mode, with CID NCE 35, $1.6 \mathrm{~m} / \mathrm{z}$ isolation window, AGC target 1E4, maximum injection time of $35 \mathrm{~ms}$, and dynamic exclusion was employed for $60 \mathrm{~s}$.

The raw data files were processed using Thermo Scientific Proteome Discoverer software version 1.4, spectra were searched against the Uniprot Mus musculus plus DT database using Sequest HT search engine. Search results were trimmed to a $1 \%$ FDR using Percolator. For the trypsin, up to two missed cleavages were allowed. MS tolerance was set $10 \mathrm{ppm}$; MS/MS tolerance 0.6 Da. Carbamidomethylation on cysteine residues was used as fixed modification; oxidation of methione as well as phosphorylation of serine, threonine and tyrosine was set as variable modifications.

\section{Western blots}

For western blots, frozen punched dBNST brain tissues ( $n=6$ from WT, and $n=4$ for cas 9 mediated knockoff of 
Gabra5, $20 \mathrm{mg}$ ) were thawed and homogenized in $100 \mu \mathrm{l}$ RIPA lysis buffer supplemented with protease inhibitor cocktail (Millipore Inc., Billerica, MA, USA). The lysates were centrifuged at $14,000 \times g$ at $4{ }^{\circ} \mathrm{C}$ for $30 \mathrm{~min}$ and the supernatants were collected and stored at $-20^{\circ} \mathrm{C}$ until use. Protein concentration was determined by the Bio-Rad DC protein assay (Bio-Rad Laboratories Inc., Hercules, CA, USA). Each sample of $50 \mu \mathrm{g}$ protein was separated by $10 \%$ SDS-PAGE electrophoresis using 100 Volt for $2 \mathrm{~h}$ and then transferred to a PVDF membrane at $100 \mathrm{~mA}$ for $2 \mathrm{~h}$. The membrane was blocked with $5 \%$ non-fat dry milk for $1 \mathrm{~h}$ at room temperature and then incubated overnight at $4{ }^{\circ} \mathrm{C}$ with primary antibodies diluted as followed:

GABRA5 (1:1000) (AB9678, Millipore, Billerica, MA, USA), beta-actin $(1: 10,000)$ (MAB1501, Millipore, Billerica, MA, USA). On the next day, after washing three times with $0.05 \%$ Tween-20 and phosphate-buffered saline, the membrane was incubated with the corresponding horseradish peroxidase (HRP) conjugated secondary antibody for $1 \mathrm{~h}$ at room temperature. Blots were then developed using an ECL Plus Kit (Millipore) on Fuji Medical Xray film and scanned using a Bio-Rad 6500 scanner. Optical density was quantified with Quantity One software (BioRad).

\section{Statistical analyses}

Data were analyzed by one-way ANOVA or two-way ANOVA with the post hoc as appropriate. Statistical analyses were performed using Prism software (GraphPad Software) Results were considered significantly different at $P<0.05$. All data are presented as mean \pm SEM.

Acknowledgements The $M c 4 r^{C r e}$ mice were gifts kindly provided by Bradford Lowell (Beth Israel Deaconess Medical Center, Harvard Medical School). The $A A V-D I O-C h R 2$ backbone plasmid was a gift kindly provided by Scott Sternson (HHMI Janelia Research Campus). The Ai14 and Ai32 mice were gifts kindly provided by Hongkui Zeng (Allen Institute for Brain Sciences). We acknowledge the Alkek Center for Molecular Discovery, the Metabolomics Core at Baylor College of Medicine for providing technical support. Some AAV vectors applied in this study were packaged by the Optogenetics and Viral Design/ Expression Core at Baylor College of Medicine. We acknowledge the Flow Cytometry Core Laboratory at Texas Children's Cancer and Hematology Centers for providing technical support.

Funding This work was supported by NIH grants (1R01DK109194, 1R56DK109194) to Q.W., the Pew Charitable Trust awards to Q.W., American Diabetes Association awards (\#7-13-JF-61) to Q.W., USDA/CRIS grants (3092-5-001-059) to Q.W., the Faculty Start-up grants from USDA/ARS to Q.W., Baylor Collaborative Faculty Research Investment Program grants to Q.W., NIH grants (R01DK093587, R01DK101379, and R01DK117281) to Y.Xu, USDA/CRIS grants (3092-5-001-059) to Y.X., American Heart Association awards (17GRNT32960003) to Y.X., NIH Centers of Biomedical Research Excellence, COBRE grant (P20 GM135002) and American Diabetes Association (1-17-PDF-138) to Y.H., and NIH grants R01-DA24908 to R.P. The project described was supported in part by the Neuroconnectivity Core at Baylor College of Medicine, which is supported by IDDRC Grant Number U54HD083092 from the Eunice Kennedy Shriver National Institute of Child Health \& Human Development. This work is supported in part by the Clinical and Translational Proteomics Service Center at the University of Texas Health Science Center. R.P. is a Howard Hughes Medical Institute investigator. Q.W. is a Pew Scholar of Biomedical Sciences and Kavli Scholar.

Author contributions G.X., Y.H., F.M., and Q.W. designed, analyzed, and interpreted experiments and wrote the manuscript. Q.W., and R.P. edited the manuscript. G.X., Y.H., and F.M. performed the behavioral paradigms, brain surgeries, chemogenetics, optogenetics, in vivo fiber photometry, and FACS. G.X., Y.H., F.M., and D.S. performed body weight/food intake measurement, pharmacological treatment, and immunohistochemistry. R.P. cloned and generated some AAV viral vectors. Y.H. performed electrophysiological recordings. And Y.H. and Y.X. analyzed and interpreted the electrophysiological data. M.F. performed the quantitative real-time PCR. M.D. performed the coding work for behavior test during in vivo fiber photometry recording of AgRP neurodynamics.

\section{Compliance with ethical standards}

Conflict of interest The authors declare no competing interests.

Publisher's note Springer Nature remains neutral with regard to jurisdictional claims in published maps and institutional affiliations.

Open Access This article is licensed under a Creative Commons Attribution 4.0 International License, which permits use, sharing, adaptation, distribution and reproduction in any medium or format, as long as you give appropriate credit to the original author(s) and the source, provide a link to the Creative Commons license, and indicate if changes were made. The images or other third party material in this article are included in the article's Creative Commons license, unless indicated otherwise in a credit line to the material. If material is not included in the article's Creative Commons license and your intended use is not permitted by statutory regulation or exceeds the permitted use, you will need to obtain permission directly from the copyright holder. To view a copy of this license, visit http://creativecommons. org/licenses/by/4.0/.

\section{References}

1. Collaborators GBDO, Afshin A, Forouzanfar MH, Reitsma MB, Sur P, Estep K, et al. Health effects of overweight and obesity in 195 countries over 25 years. N. Engl J Med. 2017;377:13-27.

2. Heymsfield SB, Wadden TA. Mechanisms, pathophysiology, and management of obesity. N. Engl J Med. 2017;376:254-66.

3. Ward ZJ, Bleich SN, Cradock AL, Barrett JL, Giles CM, Flax C, et al. Projected U.S. state-level prevalence of adult obesity and severe obesity. N. Engl J Med. 2019;381:2440-50.

4. Pratt LA, Brody DJ. Depression and obesity in the U.S. adult household population, 2005-2010. NCHS Data Brief, 2014: p. $1-8$.

5. Diniz BS, Reynolds Iii CF, Sibille E, Bot M, Penninx B. Major depression and enhanced molecular senescence abnormalities in young and middle-aged adults. Transl Psychiatry. 2019;9:198.

6. Ogrodnik M, Zhu Y, Langhi LGP, Tchkonia T, Kruger P, Fielder $\mathrm{E}$, et al. Obesity-induced cellular senescence drives anxiety and impairs neurogenesis. Cell Metab. 2019;29:1061-77.e8. 
7. van der Klaauw AA, Farooqi IS. The hunger genes: pathways to obesity. Cell. 2015;161:119-32.

8. Xie X, Yang H, An JJ, Houtz J, Tan JW, Xu H, et al. Activation of anxiogenic circuits instigates resistance to diet-induced obesity via increased energy expenditure. Cell Metab. 2019;29:917-31.e4

9. Liu C, Lee S, Elmquist JK. Circuits controlling energy balance and mood: inherently intertwined or just complicated intersections? Cell Metab. 2014;19:902-9.

10. Atasoy D, Betley JN, Su HH, Sternson SM. Deconstruction of a neural circuit for hunger. Nature. 2012;488:172-7.

11. Betley JN, Cao ZF, Ritola KD, Sternson SM. Parallel, redundant circuit organization for homeostatic control of feeding behavior. Cell. 2013;155:1337-50.

12. Burnett CJ, Li C, Webber E, Tsaousidou E, Xue SY, Bruning JC, et al. Hunger-driven motivational state competition. Neuron. 2016;92:187-201.

13. Dietrich MO, Zimmer MR, Bober J, Horvath TL, et al. Hypothalamic Agrp neurons drive stereotypic behaviors beyond feeding. Cell. 2015;160:1222-32.

14. Garfield AS, Li C, Madara JC, Shah BP, Webber E, Steger JS, et al. A neural basis for melanocortin-4 receptor-regulated appetite. Nat Neurosci. 2015;18:863-71.

15. Krashes MJ, Shah BP, Madara JC, Olson DP, Strochlic DE, Garfield AS, et al. An excitatory paraventricular nucleus to AgRP neuron circuit that drives hunger. Nature. 2014;507:238-42.

16. Steculorum SM, Ruud J, Karakasilioti I, Backes H, Engstrom Ruud L, Timper K, et al. AgRP neurons control systemic insulin sensitivity via myostatin expression in brown adipose tissue. Cell. 2016;165:125-38.

17. Wu Q, Boyle MP, Palmiter RD. Loss of GABAergic signaling by AgRP neurons to the parabrachial nucleus leads to starvation. Cell. 2009;137:1225-34.

18. Wu Q, Clark MS, Palmiter RD. Deciphering a neuronal circuit that mediates appetite. Nature. 2012;483:594-7.

19. Livneh Y, Ramesh RN, Burgess CR, Levandowski KM, Madara JC, Fenselau H, et al. Homeostatic circuits selectively gate food cue responses in insular cortex. Nature. 2017;546:611-6.

20. Alhadeff AL, Su Z, Hernandez E, Klima ML, Phillips SZ, Holland RA, et al. A Neural circuit for the suppression of pain by a competing need state. Cell. 2018;173:140-52.e15.

21. Cedernaes J, Huang W, Ramsey KM, Waldeck N, Cheng L, Marcheva B, et al. Transcriptional basis for rhythmic control of hunger and metabolism within the AgRP neuron. Cell Metab. 2019;29:1078-91.e5

22. Padilla SL, Qiu J, Nestor CC, Zhang C, Smith AW, Whiddon BB, et al. AgRP to Kiss1 neuron signaling links nutritional state and fertility. Proc Natl Acad Sci USA. 2017;114:2413-8.

23. Padilla SL, Qiu J, Soden ME, Sanz E, Nestor CC, Barker FD, et al. Agouti-related peptide neural circuits mediate adaptive behaviors in the starved state. Nat Neurosci. 2016;19:734-41.

24. Li C, Hou Y, Zhang J, Sui G, Du X, Licinio J, et al. AGRP neurons modulate fasting-induced anxiolytic effects. Transl Psychiatry. 2019;9:111.

25. Lowell BB. New neuroscience of homeostasis and drives for food, water, and salt. N. Engl J Med. 2019;380:459-71.

26. Wu Q, Palmiter RD. GABAergic signaling by AgRP neurons prevents anorexia via a melanocortin-independent mechanism. Eur J Pharm. 2011;660:21-7.

27. Cooper SJ. Palatability-dependent appetite and benzodiazepines: new directions from the pharmacology of $\operatorname{GABA}(\mathrm{A})$ receptor subtypes. Appetite. 2005;44:133-50.

28. Luquet S, Perez FA, Hnasko TS, Palmiter RD. NPY/AgRP neurons are essential for feeding in adult mice but can be ablated in neonates. Science. 2005;310:683-5.

29. Meng F, Han Y, Srisai D, Belakhov V, Farias M, Xu Y, et al. New inducible genetic method reveals critical roles of GABA in the control of feeding and metabolism. Proc Natl Acad Sci USA. 2016;113:3645-50.

30. Tong Q, Ye CP, Jones JE, Elmquist JK, Lowell BB. Synaptic release of GABA by AgRP neurons is required for normal regulation of energy balance. Nat Neurosci. 2008;11:998-1000.

31. Lebow MA, Chen A. Overshadowed by the amygdala: the bed nucleus of the stria terminalis emerges as key to psychiatric disorders. Mol Psychiatry. 2016;21:450-63.

32. Crestani CC, Alves FH, Gomes FV, Resstel LB, Correa FM, Herman JP. Mechanisms in the bed nucleus of the stria terminalis involved in control of autonomic and neuroendocrine functions: a review. Curr Neuropharmacol. 2013;11:141-59.

33. Glangetas C, Georges F. Pharmacology of the bed nucleus of the stria terminalis. Curr Pharmacol Rep. 2016;2:262-70.

34. Marcinkiewcz CA, Mazzone CM, D'Agostino G, Halladay LR, Hardaway JA, DiBerto JF, et al. Serotonin engages an anxiety and fear-promoting circuit in the extended amygdala. Nature. 2016;537:97-101.

35. Welch JD, Kozareva V, Ferreira A, Vanderburg C, Martin C, Macosko EZ, et al. Single-cell multi-omic integration compares and contrasts features of brain cell identity. Cell. 2019;177:1873-87.e17.

36. Gafford GM, Guo J-D, Flandreau EI, Hazra R, Rainnie DG, Ressler KJ. Cell-type specific deletion of $\operatorname{GABA}(\mathrm{A}) \alpha 1$ in corticotropin-releasing factor-containing neurons enhances anxiety and disrupts fear extinction. Proc Natl Acad Sci USA. 2012;109:16330-5.

37. Wang Y, Kim J, Schmit MB, Cho TS, Fang C, Cai H. A bed nucleus of stria terminalis microcircuit regulating inflammation-associated modulation of feeding. Nat Commun. 2019;10:2769.

38. Garcia-Garcia AL, Canetta S, Stujenske JM, Burghardt NS, Ansorge MS, Dranovsky A, et al. Serotonin inputs to the dorsal BNST modulate anxiety in a 5-HT1A receptor-dependent manner. Mol Psychiatry. 2018;23:1990-7.

39. Hammack SE, Guo JD, Hazra R, Dabrowska J, Myers KM, Rainnie DG. The response of neurons in the bed nucleus of the stria terminalis to serotonin: implications for anxiety. Prog Neuropsychopharmacol Biol Psychiatry. 2009;33:1309-20.

40. Mazzone CM, Pati D, Michaelides M, DiBerto J, Fox JH, Tipton $\mathrm{G}$, et al. Acute engagement of Gq-mediated signaling in the bed nucleus of the stria terminalis induces anxiety-like behavior. Mol Psychiatry. 2018;23:143-53.

41. Fakhfouri G, Rahimian R, Dyhrfjeld-Johnsen J, Zirak MR, Beaulieu JM. 5-HT3 Receptor antagonists in neurologic and neuropsychiatric disorders: the iceberg still lies beneath the surface. Pharm Rev. 2019;71:383-412.

42. Troy AE, Simmonds SS, Stocker SD, Browning KN, et al. High fat diet attenuates glucose-dependent facilitation of 5-HT3 -mediated responses in rat gastric vagal afferents. J Physiol. 2016;594:99-114

43. Weber S, Volynets V, Kanuri G, Bergheim I, Bischoff SC. Treatment with the 5-HT3 antagonist tropisetron modulates glucose-induced obesity in mice. Int $\mathbf{J}$ Obes (Lond). 2009;33:1339-47.

44. Soto M, Herzog C, Pacheco JA, Fujisaka S, Bullock K, Clish CB et al. Gut microbiota modulate neurobehavior through changes in brain insulin sensitivity and metabolism. Mol Psychiatry. 2018;23:2287-301.

45. Cui Y, Yang Y, Ni Z, Dong Y, Cai G, Foncelle A, et al. Astroglial Kir4.1 in the lateral habenula drives neuronal bursts in depression. Nature. 2018;554:323-7.

46. Ramirez S, Liu X, MacDonald CJ, Moffa A, Zhou J, Redondo RL et al. Activating positive memory engrams suppresses depressionlike behaviour. Nature. 2015;522:335-9. 
47. Shin Yim Y, Park A, Berrios J, Lafourcade M, Pascual LM, Soares N, et al. Reversing behavioural abnormalities in mice exposed to maternal inflammation. Nature. 2017;549:482-7.

48. Kohsaka A, Laposky AD, Ramsey KM, Estrada C, Joshu C, Kobayashi Y, et al. High-fat diet disrupts behavioral and molecular circadian rhythms in mice. Cell Metab. 2007;6:414-21.

49. Betley JN, Xu S, Cao ZFH, Gong R, Magnus CJ, Yu Y, et al. Neurons for hunger and thirst transmit a negative-valence teaching signal. Nature. 2015;521:180-5.

50. Chen Y, Lin YC, Kuo TW, Knight ZA. Sensory detection of food rapidly modulates arcuate feeding circuits. Cell. 2015;160:829-41.

51. Gunaydin LA, Grosenick L, Finkelstein JC, Kauvar IV, Fenno LE, Adhikari A, et al. Natural neural projection dynamics underlying social behavior. Cell. 2014;157:1535-51.

52. Xu P, He Y, Cao X, Valencia-Torres L, Yan X, Saito K, et al. Activation of serotonin $2 \mathrm{C}$ receptors in dopamine neurons inhibits binge-like eating in mice. Biol Psychiatry. 2017;81:737-47.

53. Callaway EM, Luo L. Monosynaptic circuit tracing with glycoprotein-deleted rabies viruses. J Neurosci. 2015;35:8979-85.

54. Aponte Y, Atasoy D, Sternson SM. AGRP neurons are sufficient to orchestrate feeding behavior rapidly and without training. Nat Neurosci. 2011;14:351-5.

55. Gadde KM, Franciscy DM, Wagner HR 2nd, Krishnan KR. Zonisamide for weight loss in obese adults: a randomized controlled trial. JAMA. 2003;289:1820-5.

56. McElroy SL, Kotwal R, Guerdjikova AI, Welge JA, Nelson EB, Lake KA, et al. Zonisamide in the treatment of binge eating disorder with obesity: a randomized controlled trial. J Clin Psychiatry. 2006;67:1897-906.

57. Wallingford NM, Sinnayah P, Bymaster FP, Gadde KM, Krishnan RK, McKinney AA, et al. Zonisamide prevents olanzapineassociated hyperphagia, weight gain, and elevated blood glucose in rats. Neuropsychopharmacology. 2008;33:2922-33.

58. Wellmer J, Wellmer S, Bauer J. The impact of zonisamide on weight. A clinical study in 103 patients with epilepsy. Acta Neurol Scand. 2009;119:233-8.

59. Gadde KM, Kopping MF, Wagner HR 2nd, Yonish GM, Allison DB, Bray GA. Zonisamide for weight reduction in obese adults: a 1-year randomized controlled trial. Arch Intern Med. 2012;172:1557-64.

60. Anderson EJ, Cakir I, Carrington SJ, Cone RD, GhamariLangroudi M, Gillyard T, et al. 60 YEARS OF POMC: regulation of feeding and energy homeostasis by alpha-MSH. J Mol Endocrinol. 2016;56:T157-74.

61. Waterson MJ, Horvath TL. Neuronal regulation of energy homeostasis: beyond the hypothalamus and feeding. Cell Metab. 2015;22:962-70.

62. Herzog H. Integrated pathways that control stress and energy homeostasis. Nat Rev Endocrinol. 2020;16:75-76.

63. Berthoud HR, Munzberg H, Morrison CD. Blaming the brain for obesity: integration of hedonic and homeostatic mechanisms. Gastroenterology. 2017;152:1728-38.
64. Sternson SM, Eiselt AK. Three pillars for the neural control of appetite. Annu Rev Physiol. 2017;79:401-23.

65. Timper K, Bruning JC. Hypothalamic circuits regulating appetite and energy homeostasis: pathways to obesity. Dis Model Mech. 2017;10:679-89.

66. Rossi MA, Basiri ML, McHenry JA, Kosyk O, Otis JM, van den Munkhof HE, et al. Obesity remodels activity and transcriptional state of a lateral hypothalamic brake on feeding. Science. 2019;364:1271-4.

67. Tan Y, Hang F, Liu Z-W, Stoiljkovic M, Wu M, Tu Y, et al. Impaired hypocretin/orexin system alters responses to salient stimuli in obese male mice. J Clin Investig. 2020;130:4985-98.

68. Gross C, Zhuang X, Stark K, Ramboz S, Oosting R, Kirby L, et al. Serotonin1A receptor acts during development to establish normal anxiety-like behaviour in the adult. Nature. 2002;416:396-400.

69. Weisstaub NV, Zhou M, Lira A, Lambe E, Gonzalez-Maeso J, Hornung JP, et al. Cortical 5-HT2A receptor signaling modulates anxiety-like behaviors in mice. Science. 2006;313:536-40.

70. Rudolph U, Knoflach F. Beyond classical benzodiazepines: novel therapeutic potential of GABAA receptor subtypes. Nat Rev Drug Discov. 2011;10:685-97.

71. Leppik IE. Zonisamide: chemistry, mechanism of action, and pharmacokinetics. Seizure. 2004;13:S5-9. discussion S10.

72. Pushpakom S, Iorio F, Eyers PA, Escott KJ, Hopper S, Wells A, et al. Drug repurposing: progress, challenges and recommendations. Nat Rev Drug Discov. 2019;18:41-58.

73. Stemmer K, Muller TD, DiMarchi RD, Pfluger PT, Tschop MH. CNS-targeting pharmacological interventions for the metabolic syndrome. J Clin Invest. 2019;130:4058-71.

74. Dietrich MO, Horvath TL. Limitations in anti-obesity drug development: the critical role of hunger-promoting neurons. Nat Rev Drug Discov. 2012;11:675-91.

75. van den Pol AN, Yao Y, Fu LY, Foo K, Huang H, Coppari R, et al. Neuromedin $\mathrm{B}$ and gastrin-releasing peptide excite arcuate nucleus neuropeptide $\mathrm{Y}$ neurons in a novel transgenic mouse expressing strong Renilla green fluorescent protein in NPY neurons. J Neurosci. 2009;29:4622-39.

76. Madisen L, Mao T, Koch H, Zhuo JM, Berenyi A, Fujisawa S, et al. A toolbox of Cre-dependent optogenetic transgenic mice for light-induced activation and silencing. Nat Neurosci. 2012; 15:793-802.

77. Platt RJ, Chen S, Zhou Y, Yim MJ, Swiech L, Kempton HR, et al. CRISPR-Cas9 knockin mice for genome editing and cancer modeling. Cell. 2014;159:440-55.

78. Zhang F, Wang LP, Brauner M, Liewald JF, Kay K, Watzke N, et al. Multimodal fast optical interrogation of neural circuitry. Nature. 2007;446:633-9.

79. He Y, Shu G, Yang Y, Xu P, Xia Y, Wang C, et al. A small potassium current in AgRP/NPY neurons regulates feeding behavior and energy metabolism. Cell Rep. 2016;17:1807-18. 